\title{
Enhancing the effectiveness of androgen deprivation in prostate cancer by inducing Filamin A nuclear localization
}

\author{
Benjamin A Mooso ${ }^{1,2}$, Ruth L Vinall,t, Clifford G Tepper ${ }^{2}$, Rosalinda M Savoy ${ }^{2}$, \\ Jean P Cheung ${ }^{2}$, Sheetal Singh ${ }^{1,2}$, Salma Siddiqui ${ }^{1}$, Yu Wang ${ }^{2, \neq}$, \\ Roble G Bedolla', Anthony Martinez, Maria Mudryj ${ }^{3}, 2$, Hsing-Jien Kung', \\ Ralph $W$ deVere White ${ }^{2}$ and Paramita M Ghosh ${ }^{1,2}$
}

\footnotetext{
${ }^{1}$ VA Northern California Health Care System, Mather, California, USA

${ }^{2}$ Department of Urology, University of California Davis School of Medicine, 4860 Y Street, Suite 3500, Sacramento, California 95817, USA

${ }^{3}$ University of Texas Health Science Center at San Antonio, San Antonio, Texas, USA

(Correspondence should be addressed to P M Ghosh at Department of Urology, University of California Davis School of Medicine; Email: paramita.ghosh@ucdmc.ucdavis.edu)
}

${ }^{\dagger}(R L$ Vinall is now at California Northstate College of Pharmacy, Rancho Cordova, California, USA) ${ }^{\ddagger}(Y$ Wang is now at Lerner Research Institute, Cleveland Clinic Foundation, Cleveland, Ohio, USA)

\begin{abstract}
As prostate cancer (CaP) is regulated by androgen receptor (AR) activity, metastatic $\mathrm{CaP}$ is treated with androgen deprivation therapy (ADT). Despite initial response, patients on ADT eventually progress to castration-resistant $\mathrm{CaP}$ (CRPC), which is currently incurable. We previously showed that cleavage of the $280 \mathrm{kDa}$ structural protein Filamin A (FInA) to a $90 \mathrm{kDa}$ fragment, and nuclear localization of the cleaved product, sensitized CRPC cells to ADT. Hence, treatment promoting FInA nuclear localization would enhance androgen responsiveness. Here, we show that FInA nuclear localization induced apoptosis in CRPC cells during ADT, identifying it as a treatment tool in advanced CaP. Significantly, the natural product genistein combined polysaccharide (GCP) had a similar effect. Investigation of the mechanism of GCP-induced apoptosis showed that GCP induced FInA cleavage and nuclear localization and that apoptosis resulting from GCP treatment was mediated by FInA nuclear localization. Two main components of GCP are genistein and daidzein: the ability of GCP to induce G2 arrest was due to genistein whereas sensitivity to ADT stemmed from daidzein; hence, both were needed to mediate GCP's effects. FInA cleavage is regulated by its phosphorylation; we show that ADT enhanced FInA phosphorylation, which prevented its cleavage, whereas GCP inhibited FInA phosphorylation, thereby sensitizing $\mathrm{CaP}$ cells to ADT. In a mouse model of $\mathrm{CaP}$ recurrence, GCP, but not vehicle, impeded relapse following castration, indicating that GCP, when administered with ADT, interrupted the development of CRPC. These results demonstrate the efficacy of GCP in promoting FInA nuclear localization and enhancing androgen responsiveness in CaP.
\end{abstract}

Endocrine-Related Cancer (2012) 19 759-777

\section{Introduction}

Prostate cancer $(\mathrm{CaP})$, both localized and involving distant metastases, depends on the androgen receptor (AR) for growth and survival. Therefore, metastatic $\mathrm{CaP}$ is treated with androgen deprivation therapy (ADT; Catalona 1994); however, patients on this treatment eventually relapse, indicative of the development of castration-resistant $\mathrm{CaP}$ (CRPC). Although a number of FDA-approved treatments for CRPC are currently available, the condition remains essentially incurable, with high mortality rates. Response rate to ADT and time to progression, however, vary among 
patients, and therefore, the goal of the present project was to conduct preclinical studies to identify therapy that ensures sensitivity to ADT in the majority of patients, in order to increase the survival rate in this population.

Previously, we demonstrated that the structural protein Filamin A (FlnA), which promotes actin stress fiber formation in the cytoplasm, is localized to the nucleus of androgen-dependent cells, where it impeded CRPC development (Wang et al. 2007, Bedolla et al. 2009). $88.4 \%$ of metastatic deposits from CRPC patients expressed cytoplasmic FlnA, whereas $75 \%$ of hormone-naïve localized tumors expressed nuclear FlnA (Bedolla et al. 2009). In support of these observations, in vitro studies showed that cytoplasmic localization of FlnA was associated with increased cell motility and invasion (Bedolla et al. 2009) whereas nuclear localization was associated with castrationsensitive growth (Wang et al. 2007). Our results indicated that therapies that promoted the induction of FlnA nuclear translocation would enhance the effectiveness of ADT. The overall goal of these studies was to identify a clinically safe drug that can promote FlnA localization to the nucleus.

Full-length FlnA (280 kDa) is mainly cytoplasmic and consists of an N-terminal actin-binding domain followed by 24 repeats, each 96-amino acids long, interrupted by two hinge domains $\mathrm{H} 1$ and $\mathrm{H} 2$ (van der Flier \& Sonnenberg 2001). Proteolysis of FlnA by cleavage at $\mathrm{H} 1$ between repeats 15 and 16 created a $170 \mathrm{kDa}$ N-terminal fragment and a $110 \mathrm{kDa}$ C-terminal fragment, which was further cleaved at $\mathrm{H} 2$ between repeats 23 and 24, to yield a $90 \mathrm{kDa}$ fragment, which can translocate to the nucleus. Surprisingly, FlnA was also found to localize to the nucleolus, where it inhibited rRNA production (Deng et al. 2012), but the mechanism of transportation to that organelle is currently unknown. The hinge domain of the AR binds to the C-terminal domain of FlnA at repeats 18-19 and co-localizes to the nucleus (Ozanne et al. 2000, Loy et al. 2003). Phosphorylation of FlnA at Ser 2152 prevented cleavage of the protein (Gorlin et al. 1990), whereas dephosphorylation of FlnA induced nuclear localization and promoted sensitivity to ADT (Wang et al. 2007, Bedolla et al. 2009). Despite the attractiveness of using FlnA to enhance androgen sensitivity, the translational potential of these studies, until now, was impeded by a lack of clinically safe drugs that prevent FlnA phosphorylation and promote its cleavage.

Here, for the first time, we show that genistein combined polysaccharide (GCP), a natural product, induces FlnA nuclear localization. GCP consists of 9\% genistein, $6 \%$ daidzein, $2 \%$ glycetin, $3 \%$ equol, $15 \%$ lipid, 5\% protein, and $60 \%$ carbohydrate (deVere White et al. 2010). An initial case study reported that $1.5 \mathrm{~g} \mathrm{GCP}$ daily for 6 weeks caused tumor regression in a 63-year-old man presenting with T3, Gleason grade 6 $(3+3) \mathrm{CaP}$, and reduced serum levels of prostatespecific antigen (PSA) from 19.4 to $10.2 \mathrm{ng} / \mathrm{ml}$ in 3 weeks, indicative of reduction in AR activity (Ghafar et al. 2002). Following this report, the effect of GCP in $\mathrm{CaP}$ was investigated in a number of laboratories. In vitro and in vivo studies revealed that GCP reduced cell growth in both androgen-dependent and -independent cells (Bemis et al. 2004, Vinall et al. 2007). GCP markedly suppressed mTOR-p70S6K signaling and attenuated excessive androgen signaling, which is a hallmark of advanced $\mathrm{CaP}$ (Tepper et al. 2007, Vinall et al. 2007).

Clinical studies from our institute in men with localized CaP demonstrated the safety of GCP and resulted in no change or decline in PSA (deVere White et al. 2004). In an additional study of GCP alone in men with a diagnosis of $\mathrm{CaP}$ but no prior treatment, participants showed no evidence of metastasis; however, serum genistein levels did not correlate with PSA (deVere White et al. 2010). These studies encouraged investigation of GCP in advanced disease. In vitro studies showed that GCP treatment in combination with AR knockdown (Vinall et al. 2007) or co-treatment with the AR antagonist bicalutamide (Burich et al. 2008) had enhanced efficacy. However, the mechanism of enhanced efficacy of GCP in the absence of androgens was unknown. Although GCP is known to inhibit the PI3K/Akt/mTOR pathway, its effect on AR suppression was independent of this pathway (Tepper et al. 2007). The lack of a mediator of GCP action on the AR severely impaired efforts to understand its role in CaP control, until now.

Collaboration between two independent teams investigating the actions of GCP and FlnA, as shown here, finally led to the demonstration that GCP targets FlnA and cleaves this molecule to the $90 \mathrm{kDa}$ fragment, which can then translocate to the nucleus and impede relapse following ADT. Our results show that nuclear localization of FlnA promotes androgen dependence and that the cooperative effect of GCP and ADT in CaP results from simultaneous effects of these two treatments on this molecule both in vitro and in vivo. Our results therefore identify GCP-induced FlnA nuclear localization as a therapeutic module that enhances the efficacy of ADT. 


\section{Materials and methods}

\section{Cell culture and materials}

LNCaP and CWR22Rv1 (ATCC, Manassas, VA, USA), C4-2 cells (Urocor, Oklahoma City, OK, USA), CWR-R1 cells (Dr Elizabeth Wilson, University of North Carolina), and PC-346C cells (Dr W M van Weerden, Josephine Nefkens Institute, Erasmus MC, Rotterdam, The Netherlands) were cultured in fetal bovine serum (FBS) or charcoalstripped serum (CSS) as indicated. All cell lines used here were investigated for the presence of contaminants and their cellular origins were verified before use. The following plasmids were used in the transfections: pCMV-FlnA, FlnA(16-24), and FlnA(1-15) plasmids kindly provided by Dr E W Yong, National University of Singapore, Singapore; PSA-luciferase construct (hPSA-luc) kindly provided by $\mathrm{Dr} \mathrm{XuBao}$ Shi, University of California Davis. Cells were transfected using Lipofectamine 2000 reagent (Invitrogen) according to the manufacturer's specifications based on established protocols.

\section{Materials used}

GCP and bicalutamide were kindly provided by AminoUp, Japan, and AstraZeneca, Cheshire, UK respectively. PKI(14-22) was from Calbiochem (Billerica, MA, USA), dihydrotestosterone (DHT) and genistein were from Sigma-Aldrich, and daidzein was from Fisher Scientific (Waltham, MA, USA). PKI, genistein, daidzein, and bicalutamide were dissolved in DMSO, while DHT was dissolved in ethanol. For in vitro studies, GCP was dissolved in a solution of $50 \%$ DMSO and 50\% ethanol, whereas in vivo, it was provided as a suspension in peanut oil.

\section{Subcellular fractionation}

Cells were collected in $0.5 \mathrm{ml}$ Buffer A (10 mM HEPES, pH 7.9, $10 \mathrm{mM} \mathrm{KCl,} 0.1 \mathrm{mM}$ EDTA, and $0.5 \mathrm{mM}$ dithiothreitol) containing $200 \mu \mathrm{l} 10 \%$ IGEPAL and protease inhibitors $(0.1 \mathrm{mM}$ benzamidine, $1 \mathrm{mM}$ phenylmethylsulfonyl fluoride (PMSF), and $10 \mu \mathrm{g} / \mathrm{ml}$ each phenanthroline, leupeptin, aprotinin, and pepstatin A). Following $10 \mathrm{~min}$ of incubation at room temperature, the lysates were transferred to ice and centrifuged at $4{ }^{\circ} \mathrm{C}$ at $250 \mathrm{~g}$ in a benchtop refrigerated centrifuge (Eppendorf 5417R) for $5 \mathrm{~min}$ and the supernatant collected as the cytosolic fraction. The pellet containing the nuclei was resuspended in $150 \mathrm{ml}$ Buffer B (20 mM HEPES, pH 7.9, $0.4 \mathrm{M}$ $\mathrm{NaCl}, 1 \mathrm{mM}$ EDTA, and 10\% glycerol) containing the same protease inhibitors and solubilized by vigorous shaking using a sonicator at $4{ }^{\circ} \mathrm{C}$ for $2 \mathrm{~h}$. The suspension was then centrifuged at $4{ }^{\circ} \mathrm{C}$ as before for $5 \mathrm{~min}$ and the supernatant collected as the nuclear fraction.

\section{Antibodies used}

Rabbit polyclonal antibodies against $\beta$-actin, AR, cyclin $A$, cyclin B, and cyclin D1 were from Santa Cruz Biotechnology (Santa Cruz, CA, USA). Mouse MABs against Akt, GAPDH, and $\alpha$-tubulin along with rabbit polyclonal antibodies against caspase 3, lamin A, poly (ADP-ribose) polymerase (PARP), and phosphoFlnA (S2152) were from Cell Signaling (Beverly, MA, USA). Mouse monoclonal anti-FlnA antibody (C-terminal) was from Millipore (Billerica, MA, USA), rabbit polyclonal anti-FlnA antibody (C-terminal) (for immunofluorescence) was from Abcam (Cambridge, MA, USA), and rabbit polyclonal anti-FlnA (N-terminal) was from Santa Cruz Biotechnology.

\section{RNA inhibition}

Anti-FlnA siRNA duplex with the following target sequence was purchased from Dharmacon Research, Inc., Lafayette, CO, USA: 5'-CAACGTTGGTAGTCATTGT-3'. A pool of four duplexes sold as AR siRNA (Santa Cruz Biotechnology) with the following sequences: Strand \#1: 5'-CAGUCCCACUUGUGUCAAATT-3', Strand \#2: 5'-CCUGAUCUGUGGAGAUGAATT-3' ${ }^{\prime}$, Strand \#3: 5'-GUCGUCUUCGGAAAUGUUATT-3', and Strand \#4: 5'-GACAGUGUCACACAUUGAATT- ${ }^{\prime}$. Control was a pool of four scrambled nonspecific siRNA duplex (siCONTROL Non-Targeting siRNA Pool, Dharmacon Research, Inc.).

\section{Analysis of cell proliferation or apoptosis using flow cytometry}

Cells were grown under desired conditions in $60 \mathrm{~mm}$ dishes at $1 \times 10^{6}$ cells/dish. Flow cytometry was conducted on FACSCalibur (Becton Dickinson Immunocytometry Systems, San Jose, CA, USA). Cells were illuminated with $200 \mathrm{~mW}$ of $488 \mathrm{~nm}$ light produced by an argon-ion laser and $635 \mathrm{~nm}$ light produced by a red-diode laser. Fluorescence was read through a 630/22 $\mathrm{nm}$ band-pass filter (for propidium iodide) or a 661/16 nm band-pass filter (for Annexin V-Alexa Fluor 647). Data were collected on 20000 cells as determined by forward and right angle light scatter and stored as frequency histograms; data used for cell cycle analysis were further analyzed using MODFIT (Verity Software, Topsham, ME, USA). 


\section{3-[4,5-Dimethylthiazol-2yl]-2,5-diphenyl-tetrazo- lium bromide assay}

Cells were cultured in 24-well plates and treated as indicated. Following treatment, each well was incubated with $25 \mu \mathrm{l}$ of $5 \mathrm{mg} / \mathrm{ml} \mathrm{3-[4,5-dimethylthia-}$ zol-2yl]-2,5-diphenyl-tetrazolium bromide (MTT; Sigma-Aldrich) for $1 \mathrm{~h}$ in a $5 \% \mathrm{CO}_{2}$ incubator at $37^{\circ} \mathrm{C}$, which converted the reactants to formazan in actively dividing cells. Proliferation rates were estimated by colorimetric assay reading formazan intensity in a plate reader at $562 \mathrm{~nm}$.

\section{Western blotting}

Whole-cell extracts were prepared by lysing cells in $300 \mu \mathrm{l}$ cell lysis buffer $(50 \mathrm{mM}$ Tris- $\mathrm{HCl}, \mathrm{pH} 7.4$, $150 \mathrm{mM} \mathrm{NaCl}$, and $1 \% \mathrm{NP}-40)$ containing the protease inhibitors $0.1 \mathrm{mM}$ benzamidine, $1 \mathrm{mM}$ PMSF, and $10 \mathrm{mg} / \mathrm{ml}$ each of phenanthroline, leupeptin, aprotinin, and pepstatin A and phosphatase inhibitors $20 \mathrm{mM}$ $\beta$-glycerol phosphate, $1 \mathrm{mM}$ Na-orthovanadate, and $10 \mathrm{mM} \mathrm{NaF}$. Proteins were quantitated by BCA assay (Pierce, Rockford, IL, USA) and fractionated on 29:1 acrylamide-bis SDS-PAGE. Electrophoresis was performed at $150 \mathrm{~V}$ for $2 \mathrm{~h}$ using mini vertical electrophoresis cells (Mini-PROTEAN 3 Electrophoresis Cell, Bio-Rad). The gels were electroblotted for $2 \mathrm{~h}$ at $200 \mathrm{~mA}$ using Mini Trans-Blot Electrophoretic Transfer Cell (Bio-Rad) onto $0.2 \mu \mathrm{m}$ polyvinylidene difluoride membrane (Osmonics, Westborough, MA, USA). The blots were stained overnight with primary antibodies at $4{ }^{\circ} \mathrm{C}$ and detected by enhanced chemiluminescence (Pierce) following incubation with a peroxidase-labeled secondary antibody (donkey antimouse $\mathrm{IgG}$ or goat anti-rabbit IgG, $\mathrm{F}_{\mathrm{c}}$ specific, Jackson ImmunoResearch, West Grove, PA, USA).

\section{Immunofluorescence}

Cells were rinsed with PBST (PBS with $0.05 \%$ Tween 20) and fixed with ice-cold methanol for $15 \mathrm{~min}$ at room temperature. Fixed cells were washed three times with PBST and blocked with $10 \%$ BSA for 30 min at room temperature. Primary antibody, prepared in $1 \%$ BSA, was applied to the cells, which were incubated at $4{ }^{\circ} \mathrm{C}$ overnight. Cells were then washed three times with PBST and FITC-conjugated anti-rabbit secondary antibody (Jackson ImmunoResearch), diluted 1:1000 in $1 \% \mathrm{BSA}$, was added and incubated for $30 \mathrm{~min}$ at room temperature in the dark. After washing three times with PBST, slow fade mounting medium with DAPI (Invitrogen) was applied to the slides before mounting of the coverslips.

\section{Quantitative real-time PCR}

Total cellular RNA was prepared from cells using RNeasy mini kit (Qiagen, Inc.) based on the manufacturer's protocol. cDNA was synthesized from $1 \mu \mathrm{g}$ RNA using QuantiTect reverse transcription kit based on manufacturer's protocol. cDNAs were diluted 1:4 in $\mathrm{ddH}_{2} \mathrm{O}$ and $2 \mu \mathrm{l}$ diluted cDNA were added to $5 \mu 1$ EXPRESS SYBR GreenER qPCR SuperMix (Invitrogen) and $200 \mathrm{nM}$ of each primer. GAPDH was used as the endogenous expression standard. PCR conditions were $20 \mathrm{~s}$ of initial denaturation step at $95^{\circ} \mathrm{C}, 40$ cycles at $95^{\circ} \mathrm{C}$ for $3 \mathrm{~s}$, and $60{ }^{\circ} \mathrm{C}$ for $30 \mathrm{~s}$, followed by additional 95 cycles starting at $60{ }^{\circ} \mathrm{C}$ with $0.5^{\circ} \mathrm{C}$ increase per cycle for melt curve analysis. GAPDH forward: 5'-TGCACCACCAACTGCTTA and reverse 5'-AGAGGCAGGGATGATGTTC; FlnA forward 5'-AAGTGACCGCCAATAACGAC and reverse 5'-GGCGTCACCCTGTGACTTAT.

\section{Evaluation of mouse retrovirus}

Cell lysates were prepared using RIPA Buffer containing protease and phosphatase inhibitors and normalized to $2 \mu \mathrm{g} / \mu \mathrm{l}$ using BCA Protein Assay (Pierce). Lysate $(50 \mu \mathrm{g})$ was loaded per lane, run on a $12 \%$ SDS-PAGE gel, and transferred using semidry transfer unit (Bio-Rad) at $15 \mathrm{~V}$ for $70 \mathrm{~min}$. Gag antibody (1:250) and $\beta$-actin antibody (1:10 000, Sigma A-1978) were diluted in 5\% Milk Protein TBS Tween and incubated overnight with rocking at $4{ }^{\circ} \mathrm{C}$. Membranes were washed $4 \times$ TBS Tween for $10 \mathrm{~min}$ at room temperature and then incubated with goat anti-mouse secondary antibody (1:5000, Santa Cruz SC-2005). Membranes were washed again $4 \times$ TBS Tween for $10 \mathrm{~min}$ at room temperature and incubated for $1 \mathrm{~min}$ in SuperSignal West Pico Chemiluminescent Substrate (Pierce 34080). Membranes were drained of excess fluid and images were taken using FluorChem E Imager and analyzed using AlphaView SA software (Protein Simple, Santa Clara, CA, USA).

\section{Mouse xenograft studies}

Four- to five-week-old athymic nude male mice $(n=24$, Harlan, Indianapolis, IN, USA) were implanted with $12.5 \mathrm{mg}$, 90-day release testosterone pellets (Innovative Research of America, Sarasota, FL, USA) before injection of CWR22 prostate tumor suspension s.c. in the right flank. These experiments were conducted under an IACUC approved protocol. Cells were mixed 1:1 with 50\% Matrigel (BD Biosciences, San Jose, CA, USA) before s.c. injection $\left(2.5 \times 10^{6}\right.$ cells per injection). When palpable tumors were observed, their pellets were removed, and the 
animals were left untreated $(n=6)$ or treated with vehicle $(n=8)$ or GCP $(1.2 \mathrm{mg} / \mathrm{kg}$ per day $)(n=10)$ as a suspension in water dispersed in peanut oil by esophageal gavage for 14 consecutive days, after which drug treatment was discontinued. Control animals were given water droplets dispersed in peanut oil only $(n=8)$. Uniformity of the suspension was maintained by vigorous shaking before gavage for each animal. Twenty-one days after start of experiment, the animals were castrated $(n=22)$ and/or left intact (sham operated, $n=2$ ). Sham-operated mice were opened up but then closed again without castration. Two mice from each group (sham castrated, castrated-untreated, castrated-vehicle treated, castrated-GCP treated) were killed 3 days post-castration for molecular analysis. Four others were killed due to large tumor size. The remaining 12 mice (six on GCP and six on vehicle) were used as described in the Results section. Tumor dimensions were measured twice a week using calipers. At the end of the study, tumor-bearing mice were killed using $\mathrm{CO}_{2}$ gas followed by cervical dislocation.

\section{Immunohistochemistry}

Mouse tumors were fixed in $10 \%$ buffered formalin (Medical Industries, Richmond, IL, USA) at room temperature. The tumor was paraffin embedded and processed based on established protocols. Paraffinembedded cell blocks were then sectioned and sections were heated to $60{ }^{\circ} \mathrm{C}$, cleared, and rehydrated in xylene and graded alcohols. Antigen retrieval was performed with $10 \mathrm{mM}$ citrate buffer at $\mathrm{pH} 6.0$ for $10 \mathrm{~min}$ in a pressure chamber at $121{ }^{\circ} \mathrm{C}$ and 10 more minutes without pressure. Slides were allowed to cool for another $20 \mathrm{~min}$, followed by sequential rinsing in TBS$\mathrm{T}$ (50 mM Tris-HCl, pH 7.4, $150 \mathrm{mM} \mathrm{NaCl}$, and Tween $20(0.1 \%))$. Endogenous peroxidase activity was quenched by incubation in TBS-T containing 3\% hydrogen peroxide. Slides were then blocked with $10 \%$ BSA. Each incubation step was carried out at room temperature and was followed by three sequential washes (5 min each) in TBS-T. Sections were incubated in mouse monoclonal anti-FlnA antibody against the C-terminal (Millipore), diluted in TBS-T containing $1 \%$ BSA $(1 \mathrm{~h})$, followed by incubations with biotinylated secondary antibody for $15 \mathrm{~min}$, peroxidaselabeled streptavidin for 15 min (LSAB-2 Dako Corp., Carpenteria, CA, USA), and diaminobenzidine and hydrogen peroxide chromogen substrate (Dako Corp.). Slides were counter-stained with hematoxylin and mounted. Negative controls were incubated with Universal Mouse Negative Control (Dako Corp.) in place of primary antibody.

\section{Statistical analysis}

Tumor volumes were calculated as $V=$ length $\times$ height $\times \pi / 6$. The change in tumor volume was calculated as percentage of the volume of the tumor at the time of castration. Analyses using an unpaired, two-tailed Student's $t$-test were used to compare tumor sizes of the two study groups: untreated vs GCP treated $-P<0.05$ was considered statistically significant. All in vitro experiments using MTT or luciferase data were performed in triplicate. Data are presented as relative luciferase activity using means of untreated controls as standards, normalized to the corresponding reading for $\beta$-gal.

\section{Results}

\section{Nuclear localization of a 90 kDa FInA fragment induces apoptosis in CaP cells}

We previously demonstrated that androgen-sensitive and -insensitive cell lines differentially expressed nuclear localization of FlnA, a structural protein (Wang et al. 2007, Bedolla et al. 2009). A castrateresistant subline of $\mathrm{LNCaP}$ cells, $\mathrm{C} 4-2$, has been developed from tumors obtained by co-implantation of LNCaP cells with bone stromal cells in castrated nude mice (Thalmann et al. 1994). We previously showed that C4-2 cells express very high AR transcriptional activity compared with LNCaP cells (Ghosh et al. 2005). Unlike LNCaP, C4-2 cells were not growth arrested by the anti-androgen bicalutamide (Casodex) (Fig. 1A, left), a competitive inhibitor of AR ligand binding (Masiello et al. 2002). C4-2 cells expressed lower levels of $90 \mathrm{kDa}$ FlnA compared with LNCaP (Fig. 1A, right) and lower levels of FlnA in the nucleoplasm (Fig. 1B), but not in the nucleolus. Transfection of a plasmid expressing C-terminal FlnA (FlnA 16-24), which resulted in the appearance of the $90 \mathrm{kDa}$ FlnA fragment (Loy et al. 2003, Wang et al. 2007), restored nuclear expression of FlnA in C4-2 cells (Fig. 1B). This effect required the presence of the AR because it was not observed in AR null PC-3 cells (Wang et al. 2007), but in C4-2 cells expressing full-length AR as well as CWR22Rv1 cells expressing a truncated form of AR (Fig. 1C). Transfection of FlnA 16-24, but not full-length FlnA or FlnA 1-15 (N-terminal), induced apoptosis in cells treated with the AR antagonist bicalutamide (Fig. 1D). Taken together, these results demonstrate that nuclear localization of the $90 \mathrm{kDa}$ fragment of FlnA induces apoptosis in CaP cells. 

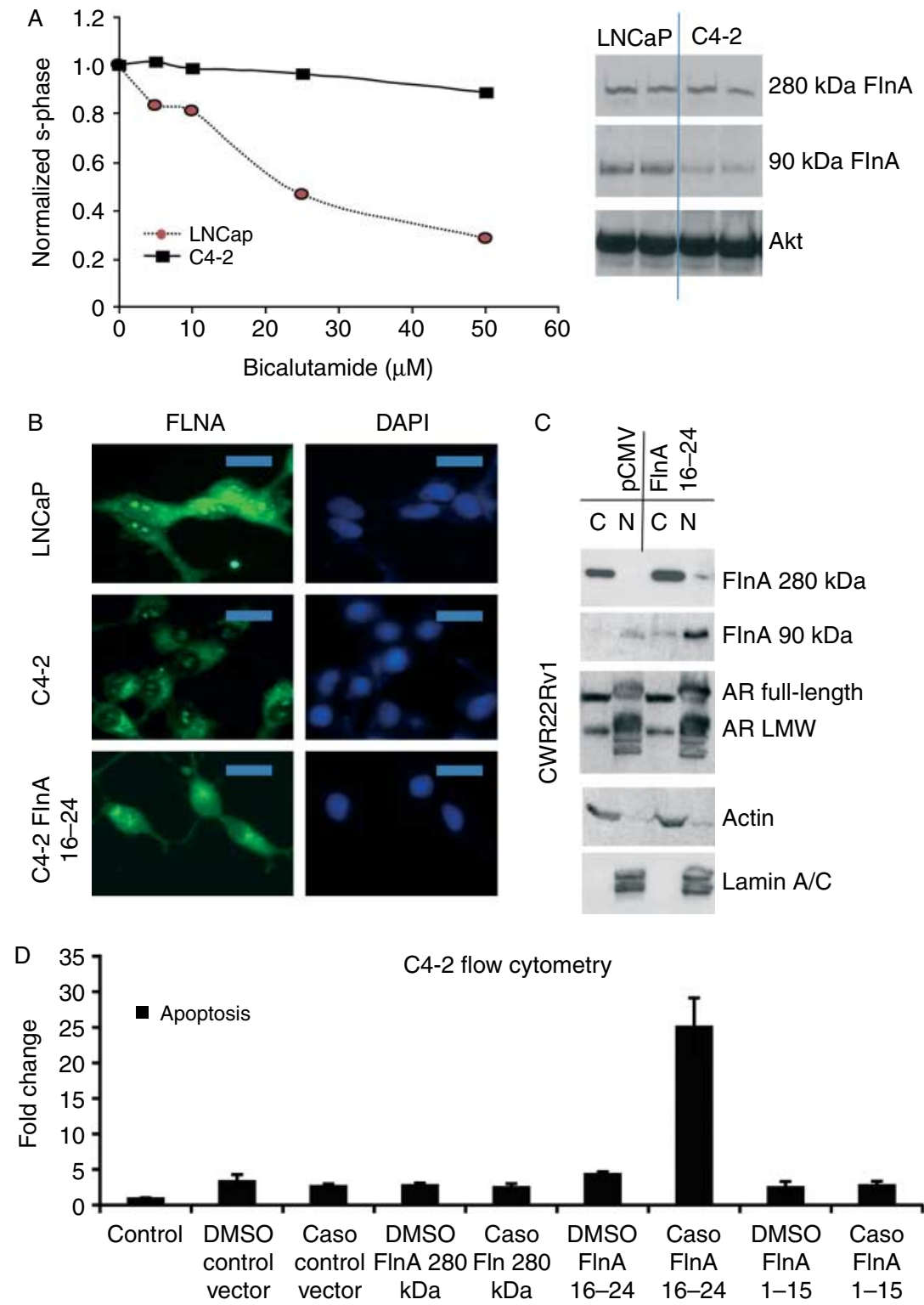

Figure 1 Nuclear localization of a $90 \mathrm{kDa}$ FlnA fragment induces apoptosis in prostate cancer cells. (A) (Left) LNCaP and C4-2 cells were treated with increasing doses of the anti-androgen bicalutamide for $48 \mathrm{~h}$ and the percentage of cells in S-phase was analyzed by flow cytometry in PI-stained cells. (Right) Untreated LNCaP and C4-2 cells. Western blotting revealed that both cell lines expressed equal levels of $280 \mathrm{kDa}$ FInA, but LNCaP cells expressed higher levels of $90 \mathrm{kDa}$ FInA compared with C4-2. (B) LNCaP, C4-2, and C4-2 cells stably transfected with FInA 16-24 (C4-2 16-24) were stained by immunofluorescence for FlnA with an antibody specific to the C-terminus of FlnA. Immunofluorescent staining shows nuclear localization of $90 \mathrm{kDa}$ FInA in LNCaP cells whereas in C4-2 cells FInA was mainly localized to the cytoplasm but not in the nucleoplasm, although bright staining in the nucleolus was also detected. In contrast, C4-2 16-24 cells expressed this protein equally in the cytoplasm and the nucleus, while nucleolar staining could still be detected. Scale bar: $10 \mu \mathrm{m}$. (C) Subcellular fractionation of CWR22Rv1 cells transfected with $1 \mu \mathrm{g} / \mathrm{ml}$ cDNA expressing FInA 16-24 showing that the 16-24 fragment goes into the nucleus. Some full-length FInA enters the nucleus when transfected with FInA 16-24 due to nucleolar localization. (D) Flow cytometric analysis in PI-stained, ethanol-fixed C4-2 cells to determine the \% cells undergoing apoptosis. Apoptosis was considered to be the cells staining with Annexin $V$ and showed that transfection with FInA 16-24 induced apoptosis in C4-2 cells. 


\section{Treatment with GCP replicates the effects of FInA nuclear localization}

The above results indicated that restoration of FlnA nuclear localization likely restored hormonesensitive behavior in CaP. Therefore, pharmaceutical approaches to FlnA cleavage were pursued. Castrationresistant CWR22Rv1 cells derived from a relapsed CWR22 tumor were chosen for these studies because they express multiple forms of AR - a $114 \mathrm{kDa}$ fulllength form containing a $\mathrm{H} 874 \mathrm{Y}$ point mutation and an in-frame tandem duplication of exon 3 , as well as truncated AR species lacking the ligand binding domain (LBD; Tepper et al. 2002). Hence, treatment that promotes hormone sensitivity in these cells would be widely applicable. Transfection of FlnA 16-24, but not full-length FlnA or FlnA 1-15, promoted expression of the $90 \mathrm{kDa}$ fragment both in the nucleus and in the cytoplasm (Fig. 2A), sensitized these cells to bicalutamide (Fig. 2B), and induced apoptosis (Fig. 2C).

The physiological range of testosterone in FBS is $55.1-97.5 \mathrm{pM}$ whereas that in CSS is $15.6-19.0 \mathrm{pM}$ (Sedelaar \& Isaacs 2009). Hence, culture in CSS results in ADT in vitro. GCP sensitized CWR22Rv1 cells to ADT, resulting in growth arrest and apoptosis (Fig. 2D), which was enhanced in low androgen levels.
This was accompanied by increases in caspase 3 and PARP cleavage, indicative of apoptosis, especially in low-androgen medium (Fig. 2E). These results demonstrated that the effect of GCP was very similar to that induced by FlnA 16-24.

\section{FInA cleavage to the $90 \mathrm{kDa}$ fragment mediates GCP-induced apoptosis}

We previously showed that the AR activated similar pathways in CWR22Rv1 and CWR-R1, two cell lines established from two independent relapsed CWR22 tumors (Chen et al. 2010a). Similar to CWR22Rv1 (Tepper et al. 2002), CWR-R1 cells were refractory to hormonal treatment (Fig. 3A); significantly, these cells were also sensitized to cytostatic effects of GCP in low-androgen media (Fig. 3B). Investigation of the mechanism of this effect indicated that GCP induced G2/M arrest in CaP cells (Fig. 3C), similar to its main component genistein as has been demonstrated by other laboratories in various cell lines (Lian et al. 1998, Schmidt et al. 2008, Zhao et al. 2009, Han et al. 2010). Further, GCP suppressed the levels of $280 \mathrm{kDa}$ FlnA while causing an increase in the levels of the cleaved FlnA levels (110 and $90 \mathrm{kDa}$ ) (Fig. 3D), thereby indicating that GCP causes FlnA cleavage.
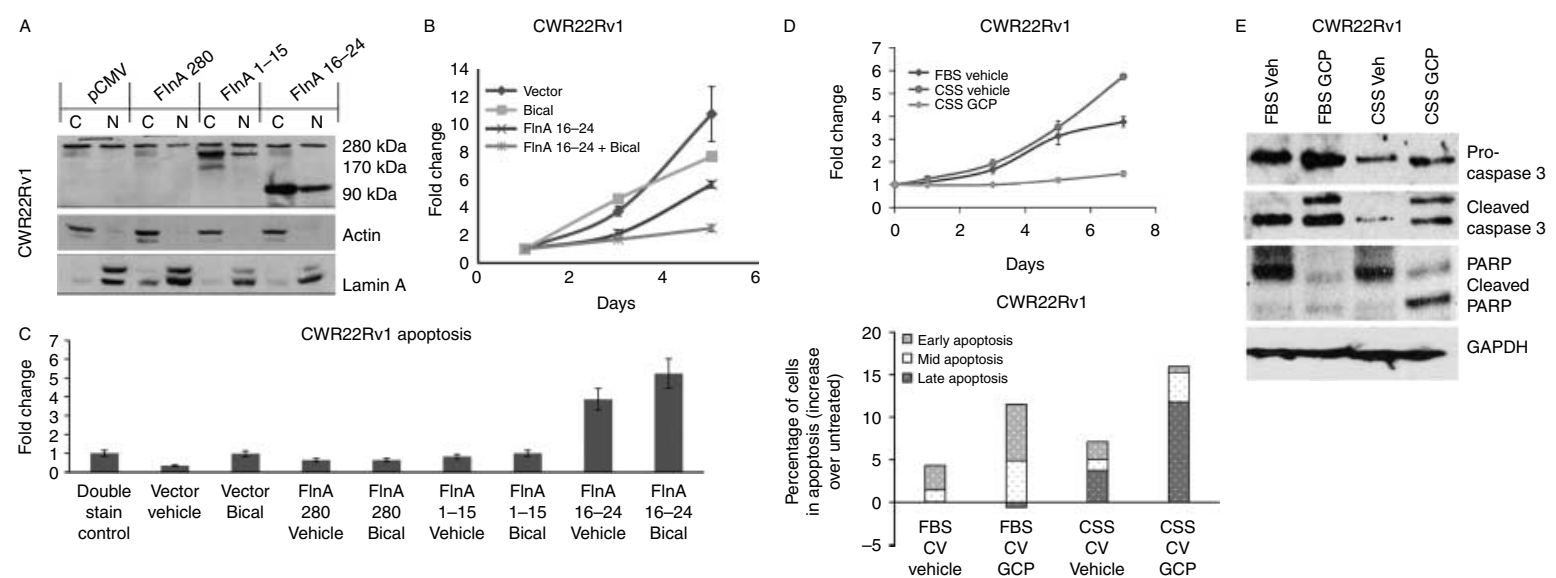

Figure 2 Treatment with genistein combined polysaccharide (GCP) replicates the effects of FlnA nuclear localization. (A) Expression of the transfected proteins when CWR22Rv1 cells were transiently transfected for $48 \mathrm{~h}$ with $2 \mu \mathrm{g} / \mathrm{ml}$ of an empty vector, full-length FInA $(280 \mathrm{kDa})$, FlnA 1-15 $(170 \mathrm{kDa})$, or FInA 16-24 $(90 \mathrm{kDa})$. Actin and lamin A were used as markers of the cytoplasm and the nucleus respectively. (B) As estimated by MTT assay, neither $10 \mu \mathrm{M}$ bicalutamide nor FInA 16-24 individually had significant effects on the growth of CWR22Rv1 cells, but in combination, they prevented cell growth. Each point on the graph represents mean \pm s.D. of three independent readings. (C) CWR22Rv1 cells underwent apoptosis when transfected with FInA 16-24 but not when transfected with an empty vector, FInA 280 or FInA 1-15 as determined by flow cytometry after $48 \mathrm{~h}$ in Annexin V-and propidium iodide-stained cells. (D) (Upper) MTT assay showing effect of CWR22Rv1 cells with GCP or vehicle in FBS- and CSS-containing medium. Each point on the graph represents mean \pm S.D. of three independent readings. (Lower) Analysis of apoptosis by flow cytometry in propidium iodide- and Annexin V-stained cells demonstrating that CWR22Rv1 cells treated with $100 \mu \mathrm{g} / \mathrm{ml} \mathrm{GCP}$ for $48 \mathrm{~h}$ experienced more apoptosis than vehicle-treated cells. Early apoptosis: Annexin V staining, mid-apoptosis: Annexin V+PI staining, late apoptosis: PI staining. Results presented represent numbers after subtraction from untreated cells. Note the increase in apoptosis in cells cultured in CSS vs FBS containing medium. (E) Western blots demonstrating that $100 \mu \mathrm{g} / \mathrm{ml} \mathrm{GCP}$ after $48 \mathrm{~h}$ increased apoptosis as demonstrated by cleaved caspase 3 and PARP levels. 


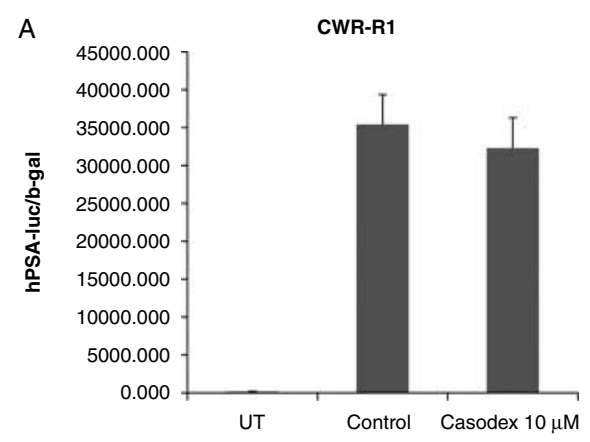

B

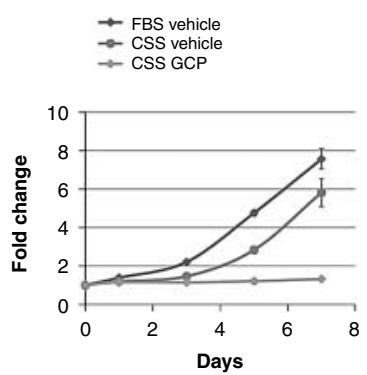

D

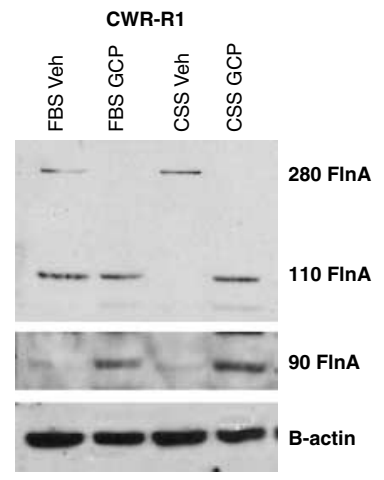

E

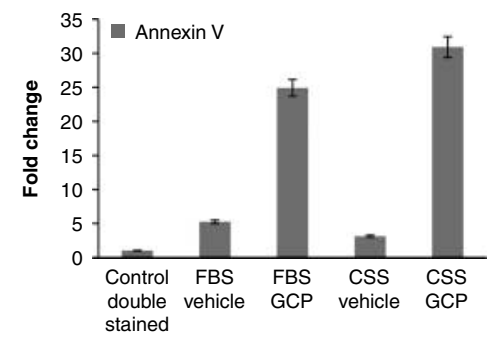

F LNCaP apoptosis

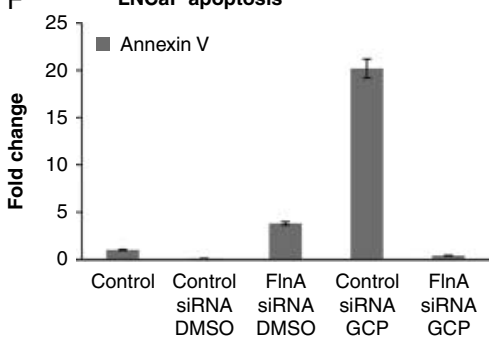

Figure 3 Treatment with GCP induces FInA cleavage to the $90 \mathrm{kDa}$ fragment that mediates GCP-induced apoptosis. (A) Luciferase assay to determine AR transcriptional activity on a PSA promoter to determine the effect of $10 \mu \mathrm{M}$ bicalutamide or vehicle in CWR-R1 cells. Cells were cultured in FBS and collected after $48 \mathrm{~h}$. Each point on the graph represents mean \pm s.D. of three independent readings. (B) MTT assay showing effect of CWR-R1 cells with GCP or vehicle in FBS and CSS containing medium. Each point on the graph represents mean \pm s.D. of three independent readings. (C) Cell cycle analysis by flow cytometry in PI-stained, ethanol-fixed cells demonstrating that CWR-R1 cells treated with $100 \mu \mathrm{g} / \mathrm{ml} \mathrm{GCP}$ for $48 \mathrm{~h}$ undergo G2/M arrest. (D) Immunoblots to determine levels of various FlnA fragments in CWR-R1 cells cultured in FBS vs CSS and treated with either vehicle or $100 \mu \mathrm{g} / \mathrm{ml} \mathrm{GCP} \mathrm{for} 48 \mathrm{~h}$. An antibody to the C-terminal end of FInA that recognizes the 280, 110, and $90 \mathrm{kDa}$ bands was used in this study. (E) Apoptosis in LNCaP cells determined by flow cytometry in Annexin V and PI stained in medium containing FBS or CSS in the presence of vehicle or $100 \mu \mathrm{g} / \mathrm{ml}$ GCP for $48 \mathrm{~h}$. (F) Role of FInA in GCP-induced apoptosis. LNCaP cells were subjected to control or FInA siRNA and treated with vehicle or $100 \mu \mathrm{g} / \mathrm{ml} \mathrm{GCP}$ for $48 \mathrm{~h}$. Apoptosis was determined by flow cytometry in cells stained with propidium iodide and Annexin V.

CWR-R1 and CWR22Rv1 lines had been propagated in mice and were contaminated by mouse retrovirus (Paprotka et al. 2011). On the other hand, LNCaP cells were free from this virus (Sfanos et al. 2011). Similar to CWR22Rv1, GCP induced apoptosis in LNCaP cells, and this effect was more prominent in CSS-cultured cells (Fig. 3E). Therefore, we investigated whether GCP-induced apoptosis was mediated by FlnA. Significantly, FlnA siRNA, but not control siRNA, prevented GCP-induced apoptosis in LNCaP cells (Fig. 3F). These results show that GCP-induced apoptosis is enhanced with ADT and is mediated by FlnA.

\section{GCP's effects reflect a combination of both genistein and daidzein}

Next, we investigated which components of GCP are responsible for its effects. In human patients, the serum levels of genistein and daidzein were determined to be
43 and $51 \mu \mathrm{mol} / \mathrm{l}$ respectively (about $10 \mu \mathrm{g} / \mathrm{ml}$ each in an average adult male), following 6 months of GCP intake at $5 \mathrm{~g} /$ day (deVere White et al. 2010). At comparable doses, daidzein reduced proliferation in the absence, rather than the presence, of androgens (22.4\% decrease in FBS, $P=0.039$, vs $69.5 \%$ decrease in CSS, $P<0.0001)$ whereas the effect of genistein remained virtually unchanged in FBS $(84.68 \%$ decrease, $P=0.002)$ vs CSS $(74 \%$ decrease, $P<0.0001$ ) (Fig. 4A). We verified these results in androgen-sensitive PC-346C CaP cells (Fig. 4B; van Weerden et al. 1996, Limpens et al. 2006) that did not express the mouse retrovirus (Fig. 4D). Genistein induced G2 arrest in PC-346C cells, while daidzein growth arrested them at G1 (Fig. 4B), while GCP resulted in growth arrest in both G1 and G2, with very few cells in S-phase. Significantly, genistein, but not daidzein, restored the levels of the $90 \mathrm{kDa}$ FlnA 

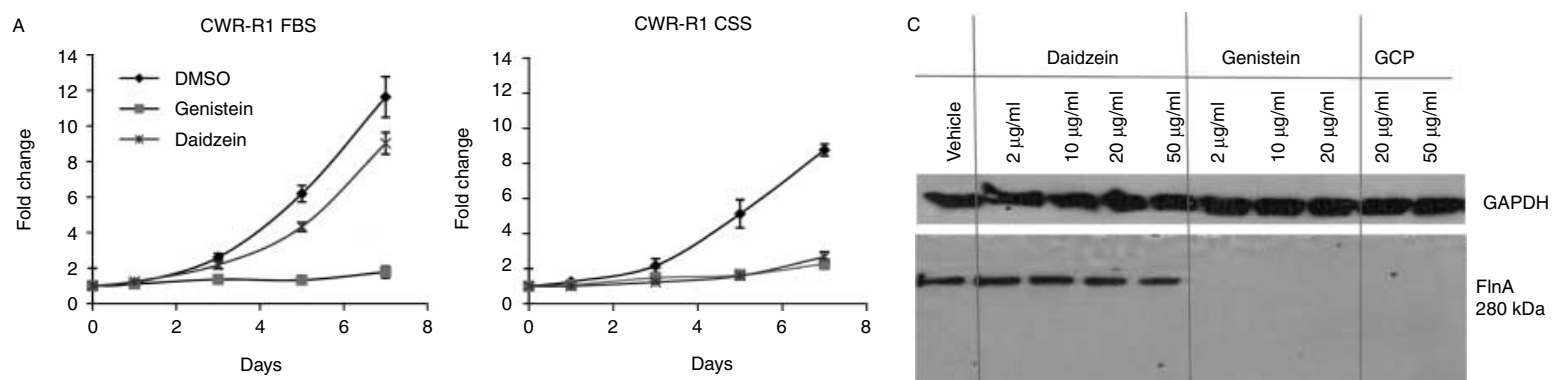

PC-346C cells $48 \mathrm{~h}$
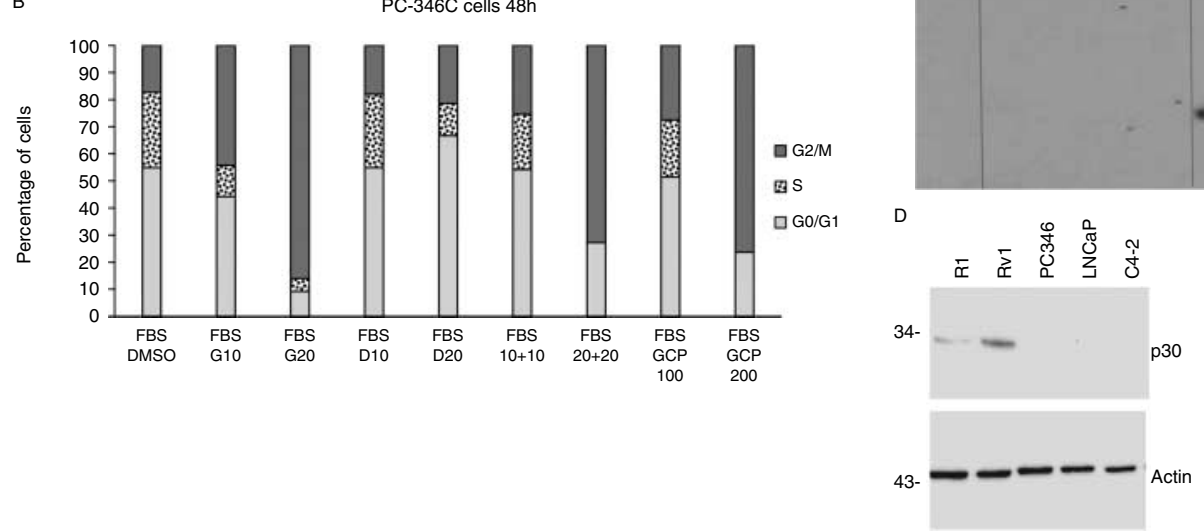

Figure $4 \mathrm{~A}$ combination of genistein and daidzein is required for rendering the effects of GCP. (A) MTT assay showing the effect of $10 \mu \mathrm{g} / \mathrm{ml}$ genistein or daidzein on CWR-R1 cells grown in either FBS- or CSS-containing medium. Each point on the graph represents mean \pm S.D. of three independent readings. (B) Cell cycle analysis by flow cytometry in PI-stained, ethanol-fixed PC-346C cells demonstrating that treatment for $48 \mathrm{~h}$ with GCP and genistein undergo G2/M arrest while cells treated with daidzein do not. Note that the combination of daidzein $(10 \mu \mathrm{g} / \mathrm{ml})$ and genistein $(10 \mu \mathrm{g} / \mathrm{ml})$ is equivalent in effect to $100 \mu \mathrm{g} / \mathrm{ml} \mathrm{GCP}$, whereas the combination of daidzein $(20 \mu \mathrm{g} / \mathrm{ml})$ and genistein $(20 \mu \mathrm{g} / \mathrm{ml})$ is equivalent in effect to $200 \mu \mathrm{g} / \mathrm{ml} \mathrm{GCP}$. (C) Western blots demonstrating that 48-h treatment with genistein and GCP, but not daidzein, increases expression of the $90 \mathrm{kDa} F \mathrm{nA}$ fragment in C4-2 cells. An antibody to the C-terminal end of FInA, which recognizes the 280, 110, and $90 \mathrm{kDa}$ bands, was used in this study. (D) To ensure that the cell lines we used (other than CWR22Rv1 and CWR22R1) do not carry murine retroviruses, we used a Gag antibody (Paprotka et al. 2011) that detects all murine retroviral gag proteins, thus offering a highly sensitive way of detecting viral infection. The cell lysates from the five cell lines were western blotted with Gag and $\beta$-actin antibodies. As expected, CWR22Rv1 and R1 express murine retroviral gag proteins, whereas others do not.

fragment (Fig. 4C). Therefore, both genistein and daidzein are needed to replicate the effects of GCP.

\section{Castration-sensitive LNCaP cells exhibited greater sensitivity to GCP + ADT compared with CRPC C4-2 cells}

$\mathrm{LNCaP}$ cells retain the ability to convert testosterone in FBS to effective levels of DHT, a stronger ligand for $\mathrm{AR}$, whereas they are unable to do so in CSS. Culture in CSS induced 55\% reduction in LNCaP cell growth $(P=0.0014)$ compared with culture in FBS. GCP treatment in FBS also reduced growth by $51 \%$ compared with vehicle $(P=0.0006)$; however, the combination of ADT and GCP decreased growth by $87 \%(P=0.0002$; Fig. 5A), demonstrating greater efficacy of GCP in lower levels of androgens. Flow cytometry showed that GCP induced G2 arrest in $\mathrm{LNCaP}$ cells in FBS, whereas in CSS, GCP also depleted cells in S-phase (Fig. 5B). Western blotting of lysates collected from GCP- and vehicle-treated cells in FBS and CSS showed that GCP treatment decreased cyclin D1 levels, completely suppressed cyclin A levels, but increased cyclin B levels, thereby supporting a G2 arrest (Fig. 5C). Further, GCP induced cleavage of PARP, especially in the presence of CSS, indicating the induction of apoptosis (Fig. 5C). Western blotting showed that GCP promoted the expression of the $90 \mathrm{kDa}$ fragment of FlnA in LNCaP cells as well, both in FBS and in CSS, similar to our observation in CWR22Rv1 (Fig. 5C).

C4-2 cells do not express inherent levels of the $90 \mathrm{kDa}$ fragment, yet GCP induced expression of the $90 \mathrm{kDa}$ fragment in these cells as well (Fig. 5D). Culture in CSS did not affect the ability of these cells to grow, despite the addition of $100 \mu \mathrm{g} / \mathrm{ml} \mathrm{GCP}$ (not shown), likely due to aberrant DHT production in C4-2 cells even from castrate levels of testosterone (Cai et al. 2011). In contrast, bicalutamide, 
A

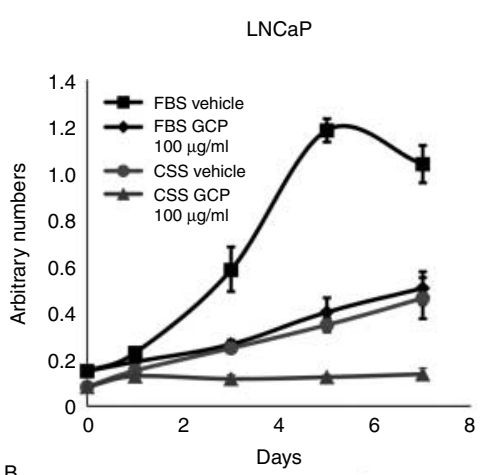

C

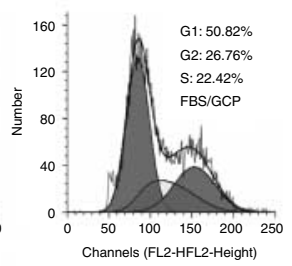

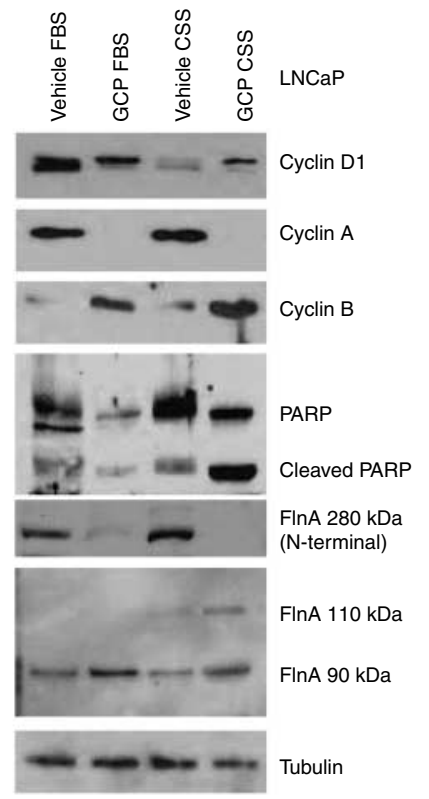

$\mathrm{D}$
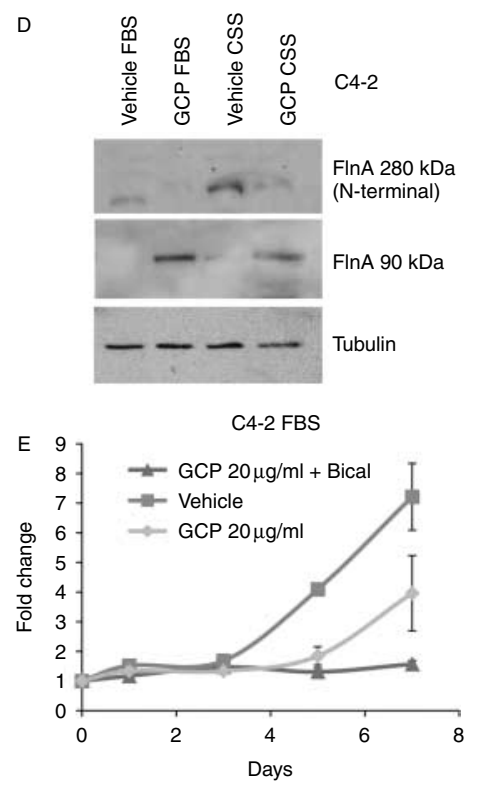
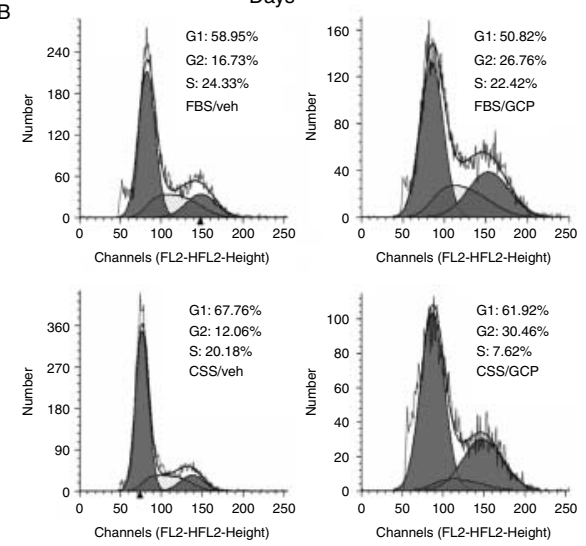

Figure $5 \mathrm{GCP}$ treatment sensitized castration-sensitive $\mathrm{LNCaP}$ cells to androgen withdrawal induced apoptosis by increasing levels of $90 \mathrm{kDa}$ FInA. (A) MTT assay in LNCaP cells showing that GCP reduced cell numbers in low-androgen media. Cells were plated in medium containing either FBS (high androgen) or CSS (low androgen) in the presence of vehicle (50\% DMSO and $50 \%$ ethanol) or $100 \mu \mathrm{g} / \mathrm{ml} \mathrm{GCP}$ for up to 7 days. Each point on the graph represents mean \pm s.D. of three independent readings. (B) Cell cycle analysis by flow cytometry in propidium iodide (PI)-stained ethanol-fixed cells demonstrating that $100 \mu \mathrm{g} / \mathrm{ml} \mathrm{GCP}$ induced cell cycle arrest in LNCaP cells cultured for $48 \mathrm{~h}$ in medium with CSS, but not FBS. In the presence of FBS, GCP induced an increase in cells in G2, only, while in CSS additionally, there was a lack of cells in S-phase. (C and D) Immunoblots to determine levels of various proteins in (C) LNCaP and (D) C4-2 cells cultured in FBS vs CSS in vehicle or $100 \mu \mathrm{g} / \mathrm{ml} \mathrm{GCP}$ for $48 \mathrm{~h}$. Note that an antibody to the N-terminal end of FlnA was used to determine the $280 \mathrm{kDa}$ band while an antibody to the C-terminal end of FlnA was used to determine the 110 and $90 \mathrm{kDa}$ bands. (E) MTT assay showing growth arrest in C4-2 cells treated with $10 \mu \mathrm{M}$ bicalutamide and $20 \mu \mathrm{g} / \mathrm{ml}$ GCP despite the continued growth in GCP alone. Each point on the graph represents mean \pm S.D. of three independent readings.

a competitive inhibitor of AR ligand binding, induced growth arrest even in the presence of $20 \mu \mathrm{g} / \mathrm{ml} \mathrm{GCP}$ in C4-2 cells (Fig. 5E). The differential effects in FBS and CSS in LNCaP cells, and CSS vs bicalutamide in C4-2, indicate that GCP is ineffective in the presence of ligands, but in the absence of ligands (with bicalutamide) is able to overcome castrate-resistant AR activation.

\section{Androgen deprivation phosphorylates FInA and prevents its cleavage to the $\mathbf{9 0} \mathrm{kDa}$ fragment}

Next, we investigated the molecular mechanism of the process by which GCP sensitized CaP cells to ADT. Prolonged culture in CSS reduced the levels of $90 \mathrm{kDa}$
FlnA (Fig. 6A), whereas supplementation of cells in CSS with $1 \mathrm{nM}$ DHT restored its levels (Fig. 6B). These results indicated that cleavage of full-length FlnA to the $90 \mathrm{kDa}$ fragment is androgen regulated, consistent with the increase in $280 \mathrm{kDa}$ FlnA with CSS seen in Figs 3D and 5C, D. This increase was not related to transcriptional control; levels of FlnA mRNA were decreased by AR siRNA, but not control siRNA (Fig. 6C), implicating the increase in $280 \mathrm{kDa}$ FlnA levels to posttranscriptional modifications. Interestingly, FlnA levels decreased both from the nucleoplasm and the cytoplasm when LNCaP cells were cultured in CSS for prolonged periods (Fig. 6D), but in the nucleolus remained unchanged. Further studies are required to explain how nucleolar FlnA is protected. 

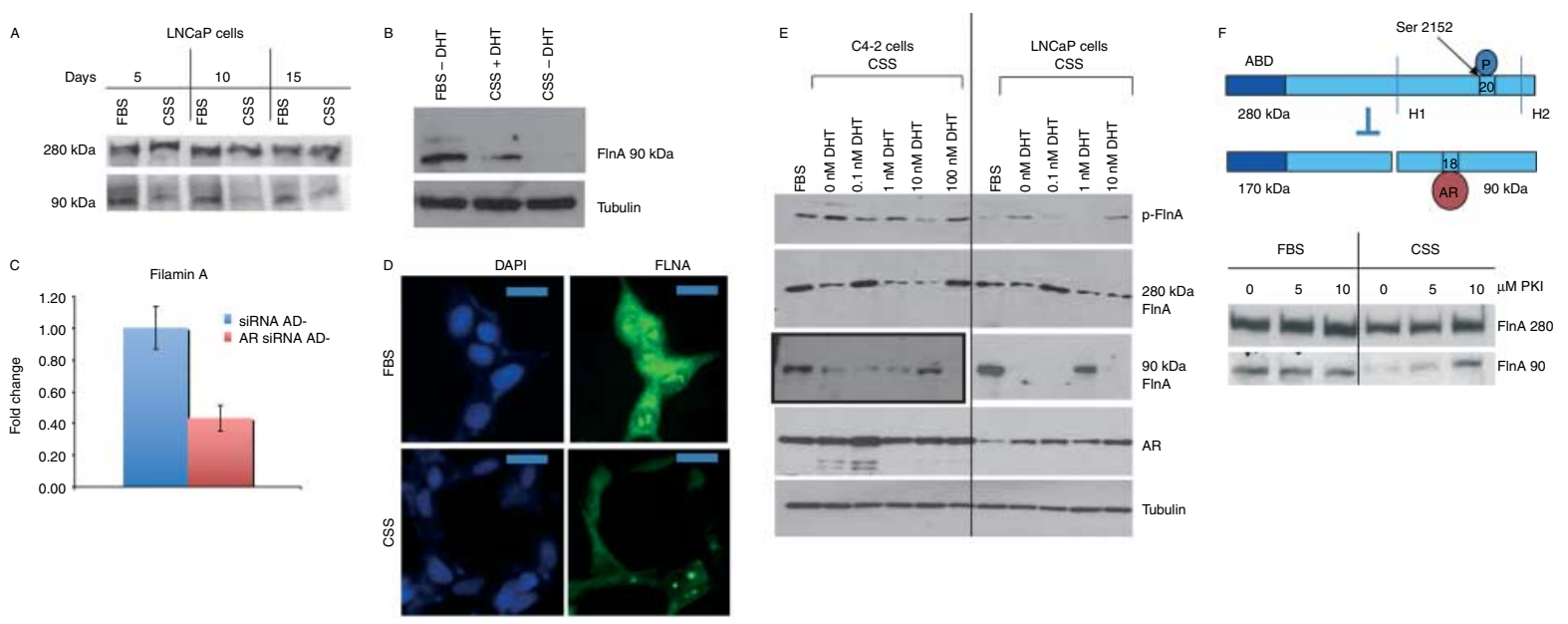

Figure 6 ADT prevents Filamin A cleavage to the $90 \mathrm{kDa}$ fragment and phosphorylates FInA at Ser 2152. (A) LNCaP cells were cultured for up to 15 days in FBS- or CSS-containing medium, and the levels of 90 and $280 \mathrm{kDa}$ FInA were determined by western blotting. (B) Western blot showing decreased expression of the $90 \mathrm{kDa}$ FInA fragment in LNCaP cells in CSS vs FBS, whereas its levels were restored by the addition of $1 \mathrm{nM} D H T$. (C) FInA expression in CWR22Rv1 cells is regulated by the AR. AR siRNA decreased FInA mRNA expression by $\sim 60 \%$ as determined by qPCR in medium with CSS (AD-). (D) LNCaP cells were grown in either FBS or CSS containing medium, and FInA protein expression was determined by immunofluorescence. Scale bar: $10 \mu \mathrm{m}$. Note that cells grown in FBS-containing medium show higher expression of FInA compared with cells grown in CSS-containing medium. (E) LNCaP and C4-2 cells were cultured in FBS or CSS with increasing levels of DHT as indicated for $48 \mathrm{~h}$. Western blots demonstrate the levels of expression of various proteins. Note that C4-2 cells actually have much lower levels of FinA $90 \mathrm{kDa}$; therefore, the blot shown here for C4-2 was at a higher exposure. (F) (Upper) Scheme showing FlnA cleavage at $\mathrm{H} 1$ is regulated by phosphorylation at Ser 2152. When FInA is phosphorylated, it does not undergo cleavage and remains in the cytoplasm, whereas upon dephosphorylation, FInA is cleaved to the $90 \mathrm{kDa}$ fragment, which translocates to the nucleus. (Lower) LNCaP cells were cultured in FBS or CSS with increasing levels of the PKA inhibitor PKI 14-22 (PKI) for $48 \mathrm{~h}$. Western blotting demonstrated that culture in CSS depleted levels of the $90 \mathrm{kDa}$ FInA, but treatment with increasing doses of PKA inhibitor in CSS-containing medium restored its expression.

C4-2 cells expressed higher levels of FlnA phosphorylation at Ser 2152 compared with LNCaP (Fig. 6E). In both cell lines, culture in CSS stimulated FlnA phosphorylation, but treatment with low doses, but not high doses, of DHT prevented ADT-induced FlnA phosphorylation (Fig. 6E). These results are consistent with the observation that low doses of DHT stimulate whereas high doses inhibit cell growth (Hofman et al. 2001). Loss of $90 \mathrm{kDa}$ FlnA coincided with an increase in FlnA phosphorylation or with an increase in $280 \mathrm{kDa} F \ln \mathrm{A}$, indicating that the level of $90 \mathrm{kDa}$ FlnA results from cleavage of the $280 \mathrm{kDa}$ form or is negatively regulated by FlnA phosphorylation. As a result, FlnA cleavage to the $90 \mathrm{kDa}$ fragment was also regulated by androgens (Fig. 6E).

Additionally, we verified that FlnA phosphorylation regulates its cleavage, using a regulator of protein kinase A (PKA), known to phosphorylate FlnA (Jay et al. 2000, 2004). As we previously showed that a PKA inhibitor increased FlnA cleavage and nuclear translocation (Bedolla et al. 2009), we treated LNCaP cells cultured in FBS or CSS with increasing concentrations of the PKA inhibitor 14-22 (PKI).
Significantly, the PKI had no effect in FBS, but in CSS medium, loss of expression of the $90 \mathrm{kDa}$ fragment was prevented by treatment with the PKI (Fig. 6F). Taken together, the above data demonstrate that ADT suppresses cleavage to $90 \mathrm{kDa}$ FlnA by enhancing phosphorylation at Ser 2152.

\section{GCP dephosphorylates FInA at Ser 2152 and promotes the formation of the $90 \mathrm{kDa}$ fragment and FInA nuclear localization}

In support of data showing that ADT prevents FlnA cleavage to the $90 \mathrm{kDa}$ fragment, $48 \mathrm{~h}$ treatment with bicalutamide depleted CWR22Rv1 cells of the $90 \mathrm{kDa}$ FlnA fragment while the level of full-length FlnA increased. In contrast, GCP increased the levels of $90 \mathrm{kDa}$ FlnA while reducing the levels of the fulllength protein (Fig. 7A, upper). Comparison of $\mathrm{LNCaP}$ and C4-2 cells with vehicle or GCP showed that GCP treatment in $\mathrm{C} 4-2$ cells restored FlnA localization to the nucleus (Fig. 7A, lower). These results prompted us to examine the role of GCP on FlnA phosphorylation.

Androgen-dependent PC-346C and LNCaP cells expressed lower levels of phospho-FlnA compared 
A
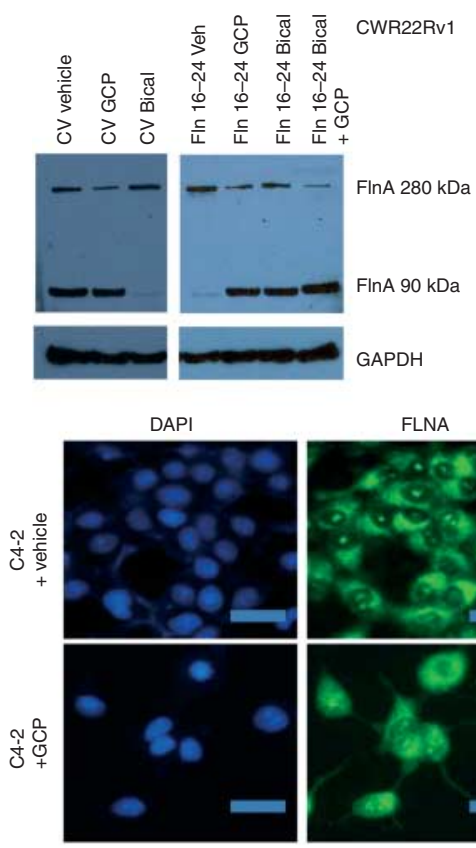

FLNA

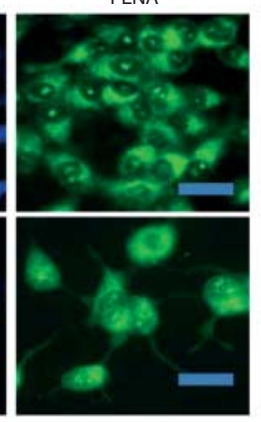

B

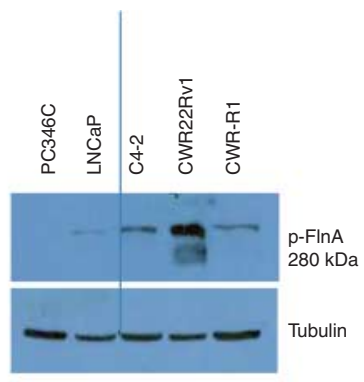

C

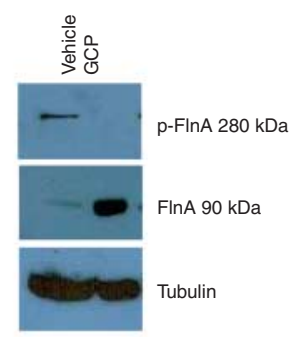

D

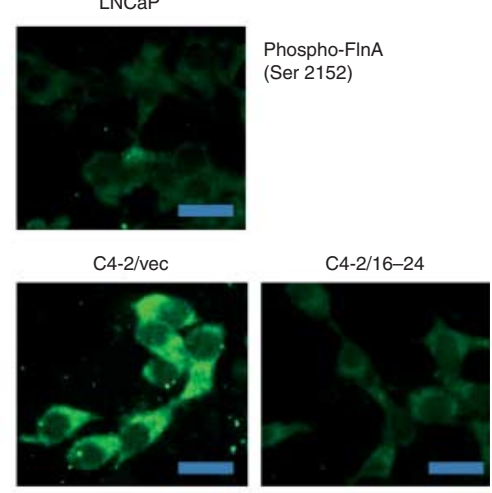

E

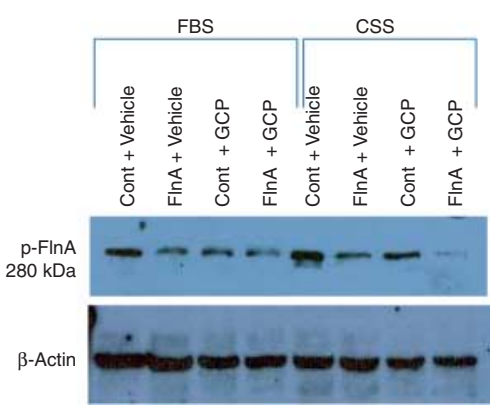

Figure 7 GCP prevents phosphorylation of full-length FInA and promotes cleavage of FlnA to its $90 \mathrm{kDa}$ fragment. (A) (Upper) Western blot showing expression of FInA in CWR22Rv1 cells. Treatment with $10 \mu \mathrm{M}$ bicalutamide depleted levels of $90 \mathrm{kDa}$ FInA while transfection with FlnA 16-24 and further treatment with $100 \mu \mathrm{g} / \mathrm{ml} \mathrm{GCP}$ for $48 \mathrm{~h}$ rescued the expression of the $90 \mathrm{kDa}$ FlnA fragment. Note higher exposure of left panel compared with right. (Lower) LNCaP and C4-2 cells treated with vehicle or $100 \mu \mathrm{g} / \mathrm{ml}$ GCP were stained with an antibody specific to the C-terminus FInA to determine subcellular localization. LNCaP cells and C4-2 cells treated with GCP showed FInA expression in the nucleus while C4-2 cells treated with vehicle showed expression only in the cytosol. Scale bar: $10 \mu \mathrm{m}$. (B) Western blot comparing levels of phosphorylated full-length FInA (Ser 2152) in various cell lines. (C) Western blot demonstrating that GCP prevented phosphorylation of full-length FInA and increased expression of $90 \mathrm{kDa} F \mathrm{lnA}$. (D) LNCaP cells and C4-2 cells transfected with vector or FInA 16-24 were stained with an antibody specific for phosphorylated FlnA (Ser 2152) and FInA phosphorylation levels determined by immunofluorescence. Scale bar: $10 \mu \mathrm{m}$. (E) LNCaP cells were cultured in medium containing either FBS or CSS and treated as indicated. Growth in CSS-containing medium increased the phosphorylation of full-length FInA while treatment with GCP reduced full-length FInA phosphorylation.

with the CRPC lines C4-2, CWR22Rv1, and CWR-R1 (Fig. 7B). Hence, we investigated the effect of GCP in CRPC cells. GCP treatment of C4-2 cells prevented FlnA phosphorylation and cleaved the protein to the $90 \mathrm{kDa}$ fragment (Fig. 7C). In support, by immunofluorescence, C4-2 cells expressed higher levels of phospho-FlnA (Ser 2152) compared with LNCaP (Fig. 7D). Incidentally, phosphorylated FlnA was localized in the cytoplasm, showing that FlnA phosphorylation prevented its nuclear translocation. Transfection with FlnA 16-24 in C4-2 cells prevented its phosphorylation, in support for a role of its effector GCP in suppressing FlnA phosphorylation. Culture in CSS increased the levels of FlnA phosphorylation at Ser 2152, which was suppressed by GCP treatment (Fig. 7E). These results show that GCP sensitizes CaP cells to ADT by preventing ADT-induced FlnA phosphorylation.

\section{GCP treatment prevented relapse in the CWR22 xenograft mouse model following ADT}

As GCP sensitized CaP cells to ADT, we investigated whether it impeded development of CRPC following ADT. Athymic nu/nu mice were s.c. implanted with CWR22 tumor extracts. When the tumors were palpable, mice were treated with GCP or vehicle as described in the Materials and methods section. Following 2 weeks of treatment, the animals underwent sham operation or were castrated; initial tumors from each group were collected 3 days post-surgery and showed strong Ki67 staining, indicative of proliferation, in sham-operated but not in castrated animals (Fig. 8A). Sham-operated, untreated tumors showed strong nuclear localization of FlnA, while castrated tumors, either untreated or treated with vehicle only, showed weak cytoplasmic, but no nuclear staining for FlnA (Fig. 8B). In contrast, castrated, 
A

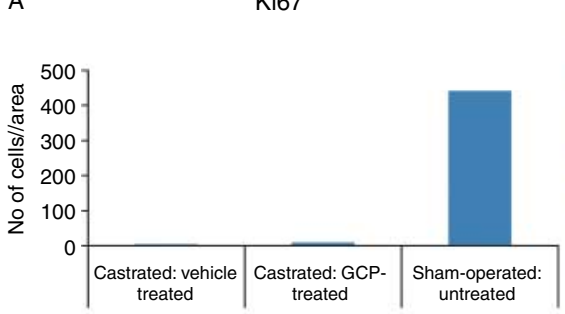

B

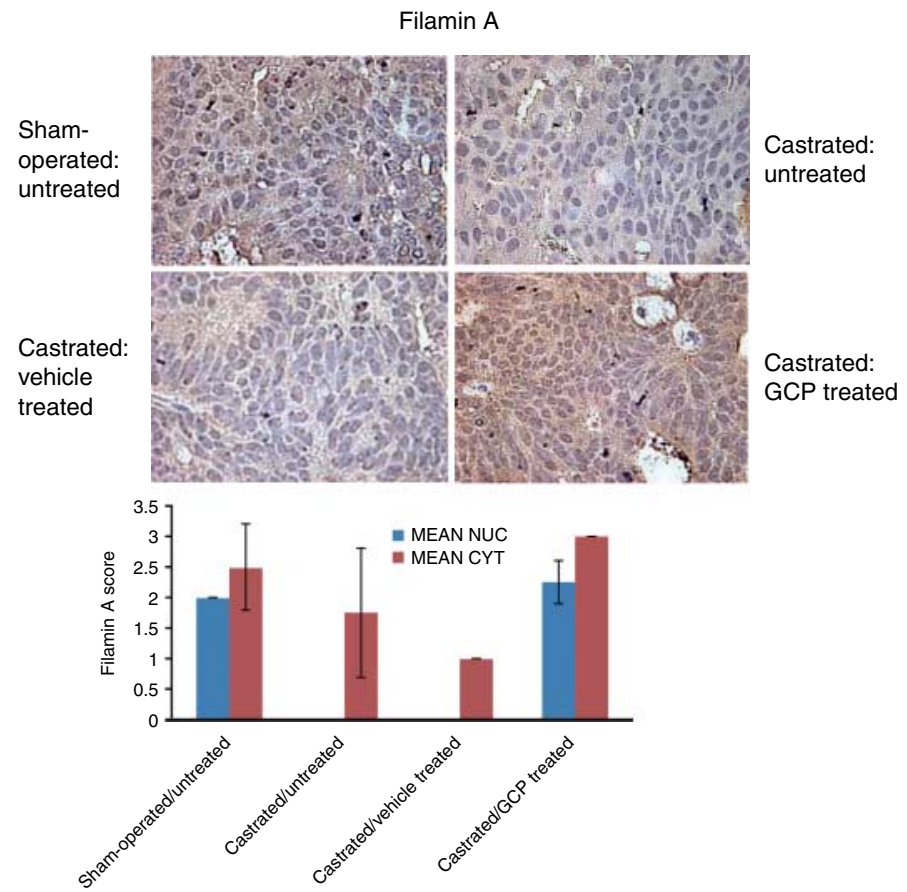

C 7 days post-castration

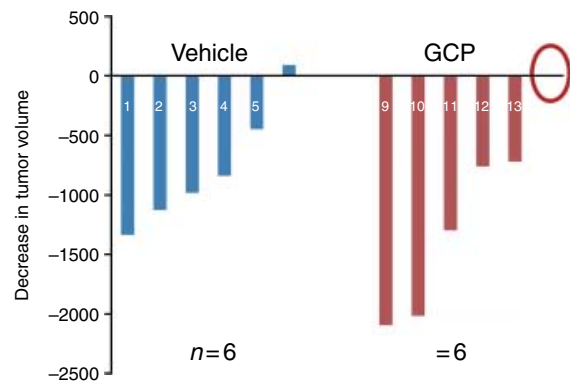

D

CWR22 xenografts

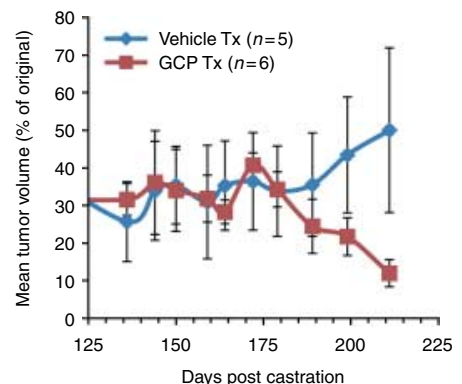

Figure $8 \mathrm{GCP}$ treatment prevented relapse in the CWR22 xenograft mouse model. (A) The tumors were paraffin-embedded, sectioned, and stained with anti-Ki67 antibody to determine the effect of GCP and castration on proliferation. Note that tumors in sham-operated animals were positive for Ki67 staining whereas those that were castrated, either in the presence or in the absence of GCP lacked this staining. Tumors were collected 3 days after the operation. (B) FInA and AR staining (brown) in tumors from animals who were i) sham operated, untreated, ii) castrated, untreated, iii) castrated, vehicle treated, and iv) castrated, GCP-treated. Note high FInA staining in the latter group. (C) Both vehicle- and GCP-treated tumors rapidly underwent tumor regression within 7 days following castration. Waterfall plot showing tumor regression in the animals 7 days post-castration. Note that GCP-treated tumors underwent greater levels of regression compared with those in vehicle-fed mice. Red circle denotes one tumor that did not undergo significant change in volume. (D) After the initial regression (up to $\sim 35$ days), tumor volume remained essentially steady until 179 days post-castration after which GCP-treated tumors continued to regress while vehicle-treated tumors began to recover and were distinctly larger than the tumors in GCP-treated mice after 211 days.

GCP-treated tumors exhibited strong FlnA staining (brown) both in the nucleus and in the cytoplasm (Fig. 8B). Within the first 7 days following castration, the tumors in GCP-treated mice regressed (mean reduction $\left.1148 \mathrm{~mm}^{3}, n=6\right)$ compared with vehicletreated mice (mean reduction $772 \mathrm{~mm}^{3}, n=6$ ) (Fig. 8C). The animals were monitored for up to 7 months (211 days) following castration. During this time, control CWR22 xenografts regressed approximately 38 days post-castration (mean reduction $40 \%$, $P=0.0008 ; n=6$ ), after which the tumors stabilized for several months and then relapsed after 6 months post-castration (179 days, relapse was defined as two or more consecutive increases in tumor volume $>5 \%$ each time) (one control animal had to be killed due to large tumor size). There was essentially no significant difference between the control $(n=5)$ and GCP $(n=6)$ groups until 6 months post-castration, after which, tumors in vehicle-treated mice remained steady relapsed $(P>0.05)$, whereas GCP-treated tumors continued to regress $(P=0.0056)$ (Fig. 8D). After 211 days (7 months post-castration), tumors in 
vehicle-treated mice were distinctly larger (mean reduction 50\% compared with initial tumor volumes; $P=0.25$ ) than the ones in GCP-treated mice (mean reduction $88 \%$ compared with initial volumes; $P=0.002$ ) (Fig. 8D). Taken together, these results indicated that GCP treatment prolonged the effects of castration (ADT) in this model.

\section{Discussion}

$\mathrm{CaP}$ patients with metastases, treated with $\mathrm{ADT}$, frequently relapse, leading to CRPC, which essentially remains incurable. Studies found that although proliferation indices were consistently suppressed following ADT (Westin et al. 1995, Matsushima et al. 1999), apoptosis was only partially affected (Murphy et al. 1991, Westin et al. 1995). Surviving cells likely undergo growth arrest and lie dormant following ADT, but revive when androgen-independent stimulants release them from growth arrest (Agus et al. 1999, 2002). Hence, our goal was to develop treatments that promote apoptosis during ADT in $\mathrm{CaP}$ cells. Here, we show that proteolysis of FlnA to the $90 \mathrm{kDa}$ fragment and its subsequent nuclear localization induces apoptosis and sensitizes AR-positive $\mathrm{CaP}$ cells to ADT.

Full-length FlnA is a well-known mediator of cell migration (Feng \& Walsh 2004). FlnA proteolysis has two effects: i) it prevents cell migration mediated by full-length FlnA scaffolding interaction between actin on its N-terminal end and actin-binding proteins on its C-terminal end (Bedolla et al. 2009) and ii) the C-terminal FlnA in the nucleus suppresses AR activity (Loy et al. 2003). FlnA had no effect in AR-negative PC- 3 cells but inhibited growth of not only LNCaP and C4-2 cells that express a full-length AR with a mutation in its LBD (T877A) but also CWR22Rv1 and CWR-R1 cells that express both full-length and a truncated AR lacking the LBD (Chen et al. 2010a,b). Hence, FlnA is a likely target that may serve to regulate the ability of $\mathrm{CaP}$ cells to respond to androgens, and the objective of these studies was to identify clinically safe pharmaceutical agents that regulate FlnA proteolysis.

We previously showed that FlnA cleavage to the $90 \mathrm{kDa}$ fragment and subsequent nuclear translocation suppresses migration (Bedolla et al. 2009). The repeat structure of FlnA allows it to act as scaffold regulating co-localization of various cell migration regulators such as integrins (Ott et al. 1998, D'Addario et al. 2002, Robertson et al. 2003, Travis et al. 2004) and migfilin (Das et al. 2011). Various studies have reported that FlnA promotes cell migration (Nagano et al. 2002, Gawecka et al. 2010), whereas others show that it suppresses migration (Xu et al. 2010). It is likely that the differential effect is caused by a relative expression of intact vs cleaved FlnA. Surprisingly, a recent study indicated the presence of FlnA in the nucleolus where it inhibits rRNA production (Deng et al. 2012). FlnA expresses a nucleolar localization signal, and the C-terminal end of the molecule (FlnA 16-24) is needed to inhibit rRNA proteins (Deng et al. 2012). Our results reveal that despite the decrease in cytoplasmic and nuclear levels of FlnA with ADT, the expression of nucleolar FlnA remains unchanged, indicating that it is protected from degradation. It is important to note that nucleolar FlnA is not phosphorylated (Fig. 7D), hence reflects the cleaved product as well. Further studies are required to determine whether nucleolar FlnA plays a role in AR signaling.

The data presented show that the AR affects both FlnA levels and proteolysis. Androgens promote FlnA cleavage to the $90 \mathrm{kDa}$ fragment; thus, ADT prevents FlnA cleavage and FlnA nuclear (but not nucleolar) localization. Androgens had a biphasic effect on FlnA expression and cleavage. At low androgen levels, there was very little FlnA cleavage whereas at physiological levels of DHT, FlnA cleavage was resumed, likely caused by decreased FlnA phosphorylation (Ohta \& Hartwig 1995). However, at very high levels (100 nM DHT), FlnA was again phosphorylated. Therefore, FlnA is likely cleaved and as a result remains in the nucleus only at physiological levels of androgens and is dispersed when these levels are too high or too low. Loss of $90 \mathrm{kDa}$ FlnA may be one cause for resistance to ADT in advanced $\mathrm{CaP}$.

Interestingly, GCP-induced FlnA dephosphorylation promoted FlnA cleavage and nuclear localization. AR levels regulate FlnA expression, phosphorylation, cleavage, and nuclear localization, while FlnA in turn regulates AR transcriptional activity; hence, it is not surprising that the interaction between these factors play a role in the efficacy of ADT. We show that both genistein and daidzein are needed for effective regulation - neither component of GCP, by itself, could achieve this effect. Therefore, GCP-induced G2 arrest is mediated by genistein, while in CSS (but not in FBS), daidzein induced G1 arrest, explaining why GCP caused androgen responsiveness. Other studies had noted combination effects of genistein and daidzein that may contribute to other effects of GCP noted by us. While multiple reports noted that genistein inhibits metastasis in most cancers (Pavese et al. 2010, Zhang et al. 2010), including CaP (Lakshman et al. 2008), some reports noted that genistein promoted metastasis (Nakamura et al. 2011). Daidzein appears to 
prevent genistein-induced metastasis in some models (Singh-Gupta et al. 2010), but not in others (MartinezMontemayor et al. 2010). Our data indicate that the effect of dietary isoflavones on tumor promotion and metastasis may be related to the ability of the isoflavones to induce FlnA proteolysis.

The kinase mediating FlnA phosphorylation has not yet been identified. The Ser 2152 site on FlnA is a substrate for $\mathrm{p} 90^{\mathrm{RSK}}$ (Woo et al. 2004), PKA (Jay et al. 2000, 2004), and PKC $\alpha$ (Tigges et al. 2003), which are likely candidates. We previously showed that ADT causes the upregulation of ErbB3, a member of the EGFR family (Chen et al. 2010c, 2011). This family stimulates not only PI3K but also the MAPK family, including JNK, which in turn activates $\mathrm{p} 90^{\mathrm{RSK}}$ (Zhang et al. 2001). On the other hand, $\mathrm{p} 90^{\mathrm{RSK}}$ is inhibited by genistein (Gwin et al. 2011) and by daidzein (Kang et al. 2007). Genistein also inhibits EGFR (Aggarwal \& Shishodia 2006) and mTOR (Anastasius et al. 2009) and members of our group had demonstrated earlier that mTOR is one of the primary targets of GCP (Tepper et al. 2007). Previous studies have indicated that MAPK regulates mTOR activity via RSK (Roux et al. 2007, Carriere et al. 2008), which may indicate a prominent role for this kinase in GCP-mediated FlnA proteolysis.

Several lines of evidence indicate that GCP-induced FlnA cleavage prevents ligand-independent AR transcriptional activity. First of all, GCP inhibited growth of androgen-dependent LNCaP cells in CSS but had no effect on C4-2 cells in CSS, whereas in the presence of bicalutamide, GCP induced growth arrest in C4-2 cells. Upon ligand binding, the AR undergoes a conformational change that allows it to enter the nucleus and induce transcriptional activity (Kuil et al. 1995). In some CRPC cells, the AR can be activated by nonspecific ligands that allow the cells to propagate in CSS and also by ligand-independent AR conformational change, which induces resistance to antiandrogens such as bicalutamide (Feldman \& Feldman 2001). Hence, GCP was able to prevent ligandindependent $\mathrm{AR}$ activity and overcome the effects of bicalutamide but was ineffective when aberrant ligands activated the AR. Second, GCP and FlnA 16-24 induced growth arrest in CWR22Rv1 cells expressing a truncated AR lacking the LBD. Our data indicate that this effect can be prevented by the presence of nuclear FlnA, but further studies are needed to elucidate the mechanism by which FlnA promotes this effect. In this respect, FlnA is distinct from other AR co-repressors such as NCoR and SMRT and likely explains results showing the inability of the latter to inhibit AR activity in CRPC lines (Laschak et al. 2011).
Finally, we show that in the CWR22 androgendependent xenograft model, relapsed tumors following castration were observed in vehicle-treated but not GCP-treated mice, although both tumors regressed at similar rates. This was accompanied by induction of FlnA in GCP. Our current and previous results (Wang et al. 2007) reveal that nuclear localization of the $90 \mathrm{kDa}$ Fln A fragment sensitizes $\mathrm{CaP}$ cells to the effects of ADT. These results indicate that due to increased nuclear FlnA, co-administration of GCP together with ADT may be an important therapeutic strategy to prevent CRPC development.

\section{Declaration of interest}

The authors declare that there is no conflict of interest that could be perceived as prejudicing the impartiality of the research reported.

\section{Funding}

This work was supported by a Biomedical Laboratory Research and Development (BLRD) service Merit Award (I01BX000400) from the Department of Veterans Affairs and by R01CA133209 from the National Cancer Institute.

\section{Acknowledgements}

The authors wish to thank Christopher B Wee and Honglin Chen for their expert technical assistance in mouse xenograft and qPCR studies respectively. They also thank Dr E W Yong, National University of Singapore, Singapore, for pCMV-FlnA, FlnA(16-24), and FlnA(1-15). Human PSA-luciferase construct (hPSA-luc) was kindly provided by Dr XuBao Shi, University of California Davis, Dept of Urology. CWR-R1 cells were provided by Dr Elizabeth Wilson (University of North Carolina) while PC-346C cells were obtained from Dr W M van Weerden, Josephine Nefkens Institute. Casodex (bicalutamide) was kindly provided by AstraZeneca, Cheshire, UK, while GCP was generously provided by Amino Up, Shin-ei, Kiyota, Sapporo, Japan. The work reported here does not represent the views or opinions of the Department of Veteran Affairs or the United States Government.

\section{References}

Aggarwal BB \& Shishodia S 2006 Molecular targets of dietary agents for prevention and therapy of cancer. Biochemical Pharmacology 71 1397-1421. (doi:10.1016/ j.bcp.2006.02.009)

Agus DB, Cordon-Cardo C, Fox W, Drobnjak M, Koff A, Golde DW \& Scher HI 1999 Prostate cancer cell cycle regulators: response to androgen withdrawal and 
development of androgen independence. Journal of the National Cancer Institute 91 1869-1876. (doi:10.1093/ jnci/91.21.1869)

Agus DB, Akita RW, Fox WD, Lewis GD, Higgins B, Pisacane PI, Lofgren JA, Tindell C, Evans DP, Maiese K et al. 2002 Targeting ligand-activated ErbB2 signaling inhibits breast and prostate tumor growth. Cancer Cell 2 127-137. (doi:10.1016/S1535-6108(02)00097-1)

Anastasius N, Boston S, Lacey M, Storing N \& Whitehead SA 2009 Evidence that low-dose, long-term genistein treatment inhibits oestradiol-stimulated growth in MCF-7 cells by down-regulation of the PI3-kinase/Akt signalling pathway. Journal of Steroid Biochemistry and Molecular Biology 116 50-55. (doi:10.1016/j.jsbmb.2009.04.009)

Bedolla RG, Wang Y, Asuncion A, Chamie K, Siddiqui S, Mudryj MM, Prihoda TJ, Siddiqui J, Chinnaiyan AM, Mehra R et al. 2009 Nuclear versus cytoplasmic localization of filamin A in prostate cancer: immunohistochemical correlation with metastases. Clinical Cancer Research 15 788-796. (doi:10.1158/1078-0432.CCR-08-1402)

Bemis DL, Capodice JL, Desai M, Buttyan R \& Katz AE 2004 A concentrated aglycone isoflavone preparation (GCP) that demonstrates potent anti-prostate cancer activity in vitro and in vivo. Clinical Cancer Research 10 5282-5292. (doi:10.1158/1078-0432.CCR-03-0828)

Burich RA, Holland WS, Vinall RL, Tepper C, White RW \& Mack PC 2008 Genistein combined polysaccharide enhances activity of docetaxel, bicalutamide and Src kinase inhibition in androgen-dependent and independent prostate cancer cell lines. BJU International 102 1458-1466. (doi:10.1111/j.1464-410X.2008.07826.x)

Cai C, Chen S, Ng P, Bubley GJ, Nelson PS, Mostaghel EA, Marck B, Matsumoto AM, Simon NI, Wang H et al. 2011 Intratumoral de novo steroid synthesis activates androgen receptor in castration-resistant prostate cancer and is upregulated by treatment with CYP17A1 inhibitors. Cancer Research 71 6503-6513. (doi:10.1158/00085472.CAN-11-0532)

Carriere A, Cargnello M, Julien LA, Gao H, Bonneil E, Thibault P \& Roux PP 2008 Oncogenic MAPK signaling stimulates mTORC1 activity by promoting RSKmediated raptor phosphorylation. Current Biology 18 1269-1277. (doi:10.1016/j.cub.2008.07.078)

Catalona WJ 1994 Management of cancer of the prostate. New England Journal of Medicine 331 996-1004. (doi:10.1056/NEJM199410133311507)

Chen H, Libertini SJ, George M, Dandekar S, Tepper CG, Al-Bataina B, Kung HJ, Ghosh PM \& Mudryj M $2010 a$ Genome-wide analysis of androgen receptor binding and gene regulation in two CWR22-derived prostate cancer cell lines. Endocrine-Related Cancer 17 857-873. (doi:10.1677/ERC-10-0081)

Chen H, Libertini SJ, Wang Y, Kung HJ, Ghosh P \& Mudryj M $2010 b$ ERK regulates calpain 2-induced androgen receptor proteolysis in CWR22 relapsed prostate tumor cell lines. Journal of Biological Chemistry 285 2368-2374. (doi:10.1074/jbc.M109.049379)
Chen L, Siddiqui S, Bose S, Mooso B, Asuncion A, Bedolla RG, Vinall R, Tepper CG, Gandour-Edwards R, Shi X et al. 2010c Nrdp1-mediated regulation of ErbB3 expression by the androgen receptor in androgendependent but not castrate-resistant prostate cancer cells. Cancer Research 70 5994-6003. (doi:10.1158/00085472.CAN-09-4440)

Chen L, Mooso BA, Jathal MK, Madhav A, Johnson SD, van Spyk E, Mikhailova M, Zierenberg-Ripoll A, Xue L, Vinall RL et al. 2011 Dual EGFR/HER2 inhibition sensitizes prostate cancer cells to androgen withdrawal by suppressing ErbB3. Clinical Cancer Research 17 6218-6228. (doi:10.1158/1078-0432.CCR11-1548)

D’Addario M, Arora PD, Ellen RP \& McCulloch CA 2002 Interaction of p38 and $\mathrm{Sp} 1$ in a mechanical force-induced, $\beta 1$ integrin-mediated transcriptional circuit that regulates the actin-binding protein filamin-A. Journal of Biological Chemistry 277 47541-47550. (doi:10.1074/jbc.M20768 1200)

Das M, Ithychanda SS, Qin J \& Plow EF 2011 Migfilin and filamin as regulators of integrin activation in endothelial cells and neutrophils. PLOS ONE 6 e26355. (doi:10.1371/ journal.pone.0026355)

Deng W, Lopez-Camacho C, Tang JY, Mendoza-Villanueva D, Maya-Mendoza A, Jackson DA \& Shore P 2012 Cytoskeletal protein filamin $\mathrm{A}$ is a nucleolar protein that suppresses ribosomal RNA gene transcription. PNAS 109 1524-1529. (doi:10.1073/pnas.1107879109)

Feldman BJ \& Feldman D 2001 The development of androgen-independent prostate cancer. Nature Reviews. Cancer 1 34-45. (doi:10.1038/35094009)

Feng Y \& Walsh CA 2004 The many faces of filamin: a versatile molecular scaffold for cell motility and signalling. Nature Cell Biology 6 1034-1038. (doi:10.1038/ncb1104-1034)

van der Flier A \& Sonnenberg A 2001 Structural and functional aspects of filamins. Biochimica et Biophysica Acta 1538 99-117. (doi:10.1016/S0167-4889(01)00072-6)

Gawecka JE, Griffiths GS, Ek-Rylander B, Ramos JW \& Matter ML 2010 R-Ras regulates migration through an interaction with filamin A in melanoma cells. PLOS ONE 5 e11269. (doi:10.1371/journal.pone.0011269)

Ghafar MA, Golliday E, Bingham J, Mansukhani MM, Anastasiadis AG \& Katz AE 2002 Regression of prostate cancer following administration of genistein combined polysaccharide (GCP), a nutritional supplement: a case report. Journal of Alternative and Complementary Medicine 8 493-497. (doi:10.1089/ 107555302760253694)

Ghosh PM, Malik SN, Bedolla RG, Wang Y, Mikhailova M, Prihoda TJ, Troyer DA \& Kreisberg JI 2005 Signal transduction pathways in androgen-dependent and -independent prostate cancer cell proliferation. Endocrine-Related Cancer 12 119-134. (doi:10.1677/erc. $1.00835)$ 
Gorlin JB, Yamin R, Egan S, Stewart M, Stossel TP, Kwiatkowski DJ \& Hartwig JH 1990 Human endothelial actin-binding protein (ABP-280, nonmuscle filamin): a molecular leaf spring. Journal of Cell Biology 111 1089-1105. (doi:10.1083/jcb.111.3.1089)

Gwin J, Drews N, Ali S, Stamschror J, Sorenson M \& Rajah TT 2011 Effect of genistein on p90RSK phosphorylation and cell proliferation in T47D breast cancer cells. Anticancer Research 31 209-214.

Han H, Zhong C, Zhang X, Liu R, Pan M, Tan L, Li Y, Wu J, Zhu Y \& Huang W 2010 Genistein induces growth inhibition and G2/M arrest in nasopharyngeal carcinoma cells. Nutrition and Cancer 62 641-647. (doi:10.1080/ 01635581003605490)

Hofman K, Swinnen JV, Verhoeven G \& Heyns W 2001 E2F activity is biphasically regulated by androgens in LNCaP cells. Biochemical and Biophysical Research Communications 283 97-101. (doi:10.1006/ bbrc.2001.4738)

Jay D, Garcia EJ, Lara JE, Medina MA \& de la Luz Ibarra M 2000 Determination of a cAMP-dependent protein kinase phosphorylation site in the C-terminal region of human endothelial actin-binding protein. Archives of Biochemistry and Biophysics 377 80-84. (doi:10.1006/ abbi.2000.1762)

Jay D, Garcia EJ \& de la Luz Ibarra M 2004 In situ determination of a PKA phosphorylation site in the C-terminal region of filamin. Molecular and Cellular Biochemistry 260 49-53. (doi:10.1023/B:MCBI. 0000026052.76418.55)

Kang NJ, Lee KW, Rogozin EA, Cho YY, Heo YS, Bode AM, Lee HJ \& Dong Z 2007 Equol, a metabolite of the soybean isoflavone daidzein, inhibits neoplastic cell transformation by targeting the MEK/ERK/p90RSK/activator protein-1 pathway. Journal of Biological Chemistry $\mathbf{2 8 2}$ 32856-32866. (doi:10.1074/jbc.M701459200)

Kuil CW, Berrevoets CA \& Mulder E 1995 Ligand-induced conformational alterations of the androgen receptor analyzed by limited trypsinization. Studies on the mechanism of antiandrogen action. Journal of Biological Chemistry 270 27569-27576. (doi:10.1074/jbc.270.46. 27569)

Lakshman M, Xu L, Ananthanarayanan V, Cooper J, Takimoto CH, Helenowski I, Pelling JC \& Bergan RC 2008 Dietary genistein inhibits metastasis of human prostate cancer in mice. Cancer Research 68 2024-2032. (doi:10.1158/0008-5472.CAN-07-1246)

Laschak M, Bechtel M, Spindler KD \& Hessenauer A 2011 Inability of NCoR/SMRT to repress androgen receptor transcriptional activity in prostate cancer cell lines. International Journal of Molecular Medicine $\mathbf{2 8}$ 645-651. (doi:10.3892/ijmm.2011.735)

Lian F, Bhuiyan M, Li YW, Wall N, Kraut M \& Sarkar FH 1998 Genistein-induced G2-M arrest, p21WAF1 upregulation, and apoptosis in a non-small-cell lung cancer cell line. Nutrition and Cancer 31 184-191. (doi:10.1080/ 01635589809514701)
Limpens J, Schroder FH, de Ridder CM, Bolder CA, Wildhagen MF, Obermuller-Jevic UC, Kramer K \& van Weerden WM 2006 Combined lycopene and vitamin E treatment suppresses the growth of PC-346C human prostate cancer cells in nude mice. Journal of Nutrition 136 1287-1293.

Loy CJ, Sim KS \& Yong EL 2003 Filamin-A fragment localizes to the nucleus to regulate androgen receptor and coactivator functions. PNAS $1004562-4567$. (doi:10.1073/pnas.0736237100)

Martinez-Montemayor MM, Otero-Franqui E, Martinez J, De La Mota-Peynado A, Cubano LA \& Dharmawardhane S 2010 Individual and combined soy isoflavones exert differential effects on metastatic cancer progression. Clinical \& Experimental Metastasis 27 465-480. (doi:10.1007/s10585-010-9336-x)

Masiello D, Cheng S, Bubley GJ, Lu ML \& Balk SP 2002 Bicalutamide functions as an androgen receptor antagonist by assembly of a transcriptionally inactive receptor. Journal of Biological Chemistry 277 26321-26326. (doi:10.1074/jbc.M203310200)

Matsushima H, Goto T, Hosaka Y, Kitamura T \& Kawabe K 1999 Correlation between proliferation, apoptosis, and angiogenesis in prostate carcinoma and their relation to androgen ablation. Cancer 85 1822-1827. (doi:10.1002/ (SICI)1097-0142(19990415)85:8 < 1822::AID-CNCR24 $>3.0 . \mathrm{CO} ; 2-1)$

Murphy WM, Soloway MS \& Barrows GH 1991 Pathologic changes associated with androgen deprivation therapy for prostate cancer. Cancer 68 821-828. (doi:10.1002/ 1097-0142(19910815)68:4<821::AID-CNCR28206804 $26>3.0 . \mathrm{CO} ; 2-\mathrm{S})$

Nagano T, Yoneda T, Hatanaka Y, Kubota C, Murakami F \& Sato M 2002 Filamin A-interacting protein (FILIP) regulates cortical cell migration out of the ventricular zone. Nature Cell Biology 4 495-501. (doi:10.1038/ncb808)

Nakamura H, Wang Y, Kurita T, Adomat H \& Cunha GR 2011 Genistein increases epidermal growth factor receptor signaling and promotes tumor progression in advanced human prostate cancer. PLOS ONE 6 e 20034. (doi:10.1371/journal.pone.0020034)

Ohta Y \& Hartwig JH 1995 Actin filament cross-linking by chicken gizzard filamin is regulated by phosphorylation in vitro. Biochemistry 34 6745-6754. (doi:10.1021/ bi00020a020)

Ott I, Fischer EG, Miyagi Y, Mueller BM \& Ruf W 1998 A role for tissue factor in cell adhesion and migration mediated by interaction with actin-binding protein 280 . Journal of Cell Biology 140 1241-1253. (doi:10.1083/ jcb.140.5.1241)

Ozanne DM, Brady ME, Cook S, Gaughan L, Neal DE \& Robson CN 2000 Androgen receptor nuclear translocation is facilitated by the f-actin cross-linking protein filamin. Molecular Endocrinology 14 1618-1626. (doi:10.1210/ me.14.10.1618)

Paprotka T, Delviks-Frankenberry KA, Cingoz O, Martinez A, Kung HJ, Tepper CG, Hu WS, Fivash MJ Jr, 
Coffin JM \& Pathak VK 2011 Recombinant origin of the retrovirus XMRV. Science 333 97-101. (doi:10.1126/ science.1205292)

Pavese JM, Farmer RL \& Bergan RC 2010 Inhibition of cancer cell invasion and metastasis by genistein. Cancer Metastasis Reviews 29 465-482. (doi:10.1007/s10555010-9238-z)

Robertson SP, Twigg SR, Sutherland-Smith AJ, Biancalana V, Gorlin RJ, Horn D, Kenwrick SJ, Kim CA, Morava E, Newbury-Ecob R et al. 2003 Localized mutations in the gene encoding the cytoskeletal protein filamin A cause diverse malformations in humans. Nature Genetics $\mathbf{3 3}$ 487-491. (doi:10.1038/ng1119)

Roux PP, Shahbazian D, Vu H, Holz MK, Cohen MS, Taunton J, Sonenberg N \& Blenis J 2007 RAS/ERK signaling promotes site-specific ribosomal protein S6 phosphorylation via RSK and stimulates cap-dependent translation. Journal of Biological Chemistry $\mathbf{2 8 2}$ 14056-14064. (doi:10.1074/jbc.M700906200)

Schmidt F, Knobbe CB, Frank B, Wolburg H \& Weller M 2008 The topoisomerase II inhibitor, genistein, induces $\mathrm{G} 2 / \mathrm{M}$ arrest and apoptosis in human malignant glioma cell lines. Oncology Reports 19 1061-1066.

Sedelaar JP \& Isaacs JT 2009 Tissue culture media supplemented with $10 \%$ fetal calf serum contains a castrate level of testosterone. Prostate 69 1724-1729. (doi:10.1002/pros.21028)

Sfanos KS, Aloia AL, Hicks JL, Esopi DM, Steranka JP, Shao W, Sanchez-Martinez S, Yegnasubramanian S, Burns KH, Rein A et al. 2011 Identification of replication competent murine gammaretroviruses in commonly used prostate cancer cell lines. PLOS ONE 6 e20874. (doi:10.1371/journal.pone.0020874)

Singh-Gupta V, Zhang H, Yunker CK, Ahmad Z, Zwier D, Sarkar FH \& Hillman GG 2010 Daidzein effect on hormone refractory prostate cancer in vitro and in vivo compared to genistein and soy extract: potentiation of radiotherapy. Pharmaceutical Research 27 1115-1127. (doi:10.1007/s11095-010-0107-9)

Tepper CG, Boucher DL, Ryan PE, Ma AH, Xia L, Lee LF, Pretlow TG \& Kung HJ 2002 Characterization of a novel androgen receptor mutation in a relapsed CWR22 prostate cancer xenograft and cell line. Cancer Research 62 6606-6614.

Tepper CG, Vinall RL, Wee CB, Xue L, Shi XB, Burich R, Mack PC \& deVere White RW 2007 GCP-mediated growth inhibition and apoptosis of prostate cancer cells via androgen receptor-dependent and -independent mechanisms. Prostate 67 521-535. (doi:10.1002/pros. 20548)

Thalmann GN, Anezinis PE, Chang SM, Zhau HE, Kim EE, Hopwood VL, Pathak S, von Eschenbach AC \& Chung LW 1994 Androgen-independent cancer progression and bone metastasis in the LNCaP model of human prostate cancer. Cancer Research 54 2577-2581.
Tigges U, Koch B, Wissing J, Jockusch BM \& Ziegler WH 2003 The F-actin cross-linking and focal adhesion protein filamin $\mathrm{A}$ is a ligand and in vivo substrate for protein kinase C $\alpha$. Journal of Biological Chemistry 278 23561-23569. (doi:10.1074/jbc.M302302200)

Travis MA, van der Flier A, Kammerer RA, Mould AP, Sonnenberg A \& Humphries MJ 2004 Interaction of filamin A with the integrin $\beta 7$ cytoplasmic domain: role of alternative splicing and phosphorylation. FEBS Letters 569 185-190. (doi:10.1016/j.febslet.2004. 04.099)

Vinall RL, Hwa K, Ghosh P, Pan CX, Lara PN Jr \& deVere White RW 2007 Combination treatment of prostate cancer cell lines with bioactive soy isoflavones and perifosine causes increased growth arrest and/or apoptosis. Clinical Cancer Research 13 6204-6216. (doi:10.1158/1078-0432.CCR-07-0600)

Wang Y, Kreisberg JI, Bedolla RG, Mikhailova M, deVere White RW \& Ghosh PM 2007 A 90 kDa fragment of filamin A promotes Casodex-induced growth inhibition in Casodex-resistant androgen receptor positive C4-2 prostate cancer cells. Oncogene 26 6061-6070. (doi:10.1038/sj.onc.1210435)

van Weerden WM, de Ridder CM, Verdaasdonk CL, Romijn JC, van der Kwast TH, Schroder FH \& van Steenbrugge GJ 1996 Development of seven new human prostate tumor xenograft models and their histopathological characterization. American Journal of Pathology 149 1055-1062.

Westin P, Stattin P, Damber JE \& Bergh A 1995 Castration therapy rapidly induces apoptosis in a minority and decreases cell proliferation in a majority of human prostatic tumors. American Journal of Pathology 146 1368-1375.

deVere White RW, Hackman RM, Soares SE, Beckett LA, Li Y \& Sun B 2004 Effects of a genistein-rich extract on PSA levels in men with a history of prostate cancer. Urology 63 259-263. (doi:10.1016/j.urology.2003. 09.061)

deVere White RW, Tsodikov A, Stapp EC, Soares SE, Fujii H \& Hackman RM 2010 Effects of a high dose, aglycone-rich soy extract on prostate-specific antigen and serum isoflavone concentrations in men with localized prostate cancer. Nutrition and Cancer 62 1036-1043. (doi:10.1080/01635581.2010.492085)

Woo MS, Ohta Y, Rabinovitz I, Stossel TP \& Blenis J 2004 Ribosomal S6 kinase (RSK) regulates phosphorylation of filamin A on an important regulatory site. Molecular and Cellular Biology 24 3025-3035. (doi:10.1128/MCB.24.7. 3025-3035.2004)

Xu Y, Bismar TA, Su J, Xu B, Kristiansen G, Varga Z, Teng L, Ingber DE, Mammoto A, Kumar R et al. 2010 Filamin A regulates focal adhesion disassembly and suppresses breast cancer cell migration and invasion. Journal of Experimental Medicine 207 2421-2437. (doi:10.1084/jem.20100433) 
Zhang Y, Zhong S, Dong Z, Chen N, Bode AM \& Ma W 2001 UVA induces Ser381 phosphorylation of p90RSK/MAPKAP-K1 via ERK and JNK pathways. Journal of Biological Chemistry 276 14572-14580. (doi:10.1074/jbc.M004615200)

Zhang Y, Zhu G, Gu S, Chen X, Hu H \& Weng S 2010 Genistein inhibits osteolytic bone metastasis and enhances bone mineral in nude mice. Environmental Toxicology and Pharmacology 30 37-44. (doi:10.1016/ j.etap.2010.03.016)
Zhao R, Xiang N, Domann FE \& Zhong W 2009 Effects of selenite and genistein on G2/M cell cycle arrest and apoptosis in human prostate cancer cells. Nutrition and Cancer 61 397-407. (doi:10.1080/01635580802582751)

Received in final form 30 August 2012 Accepted 18 September 2012 Made available online as an Accepted Preprint 19 September 2012 